\title{
Optimizing the supply chain of biomass and biogas for a single plant considering mass and energy losses
}

Jensen, Ida Græsted; Münster, Marie; Pisinger, David

Published in:

European Journal of Operational Research

Link to article, DOI:

10.1016/j.ejor.2017.03.071

Publication date:

2017

Document Version

Peer reviewed version

Link back to DTU Orbit

Citation (APA):

Jensen, I. G., Münster, M., \& Pisinger, D. (2017). Optimizing the supply chain of biomass and biogas for a single plant considering mass and energy losses. European Journal of Operational Research, 262(2), 744-758.

https://doi.org/10.1016/j.ejor.2017.03.071

\section{General rights}

Copyright and moral rights for the publications made accessible in the public portal are retained by the authors and/or other copyright owners and it is a condition of accessing publications that users recognise and abide by the legal requirements associated with these rights.

- Users may download and print one copy of any publication from the public portal for the purpose of private study or research.

- You may not further distribute the material or use it for any profit-making activity or commercial gain

- You may freely distribute the URL identifying the publication in the public portal 


\title{
Optimizing the supply chain of biomass and biogas for a single plant considering mass and energy losses
}

\author{
Ida Græsted Jensen ${ }^{\mathrm{a}, 1, *}$, Marie Münster ${ }^{\mathrm{a}}$, David Pisinger ${ }^{\mathrm{a}}$ \\ ${ }^{a}$ Technical University of Denmark, DTU Management Engineering, Produktionstorvet, Building 426, DK - 2800 \\ Kongens Lyngby, Denmark
}

\begin{abstract}
The share of renewable energy in the Danish energy sector is increasing and the goal is that biogas production should reach a production level of 17 petajoules (PJ) in 2020 according to the Danish Energy Agency. However, this goal is currently not reachable due to lack of investments in biogas plants.
\end{abstract}

In this paper, a mixed integer programming (MIP) model for finding the optimal production and investment plan for a biogas supply chain is presented to ensure better economy for the full chain hopefully stimulating future investments in biogas. The model makes use of step-wise linear functions to represent capital and operational expenditures at the biogas plant; considers the chain from the farmer to the end market; and includes changes of mass and energy content along the chain by modeling the losses and gains for all processes in the chain. Biomass inputs are scheduled on a weekly basis whereas energy outputs are scheduled on an hourly basis to better capture the changes of energy prices and potentially take advantage of these changes.

The model is tested on a case study with co-digestion of straw, sugar beet and manure, considering natural gas, heat, and electricity as end products. The model finds a production and investment plan for a predefined location of the plant within half an hour of central processing unit (CPU) time. The resulting project turns out to be profitable and gives a production plan for each process, which underlines the possibilities of optimizing the processes in a biogas project.

Keywords: OR in Energy, Supply Chain Optimization, Biomass and Bioenergy Supply Chains, Network Flow Optimization

${ }^{*}$ Corresponding author: idje@dtu.dk 


\section{Introduction}

The Danish government has set an ambitious goal of having a biogas production level of 17 PJ in 2020 (Danish Energy Agency, 2012a). This goal has turned out to be hard to reach because of the lack of willingness to invest in new biogas plants. An overview of planned investments from the Danish Energy Agency shows that the goal cannot be reached even when including proposed projects which are assessed to be unlikely to go ahead (Danish Energy Agency, 2014b). Therefore, in order to stimulate future investments in biogas plants a tool for designing the optimal supply chain, size of processes, and input types to use is developed.

Denmark has a biomass potential of around 200 PJ and in order to fulfill the Danish goal of becoming independent of fossil fuel by 2050, it will be necessary to harvest this potential and utilize it optimally, thereby avoiding a potentially unsustainable level of biomass import. A high share of the available biomass, around $80 \%$, is in the shape of waste fractions from agriculture and forestry (Danish Energy Agency, 2014a). The two main waste fractions, each constituting around $40 \%$ of the waste fractions from agriculture and forestry, are manure and straw (Danish Energy Agency, 2014a). Manure can be used for biogas production, thereby creating the double benefit of producing energy and reducing emissions from spreading raw manure on fields as the digestate resulting from the anaerobic digestion has less emissions compared to manure (Wenzel et al., 2014). Manure, however, has a low biogas yield on its own, so typically additional biomass inputs are needed for co-digestion to ensure economic feasibility of biogas plants. Currently, only $5 \%$ of the manure potential is utilized (Danish Energy Agency, 2014a). After pretreatment, straw can be used as additional biomass to increase the biogas yield. Less than half of the straw potential is currently utilized for energy production, while the rest is plowed down or used as deep litter. Another possibility is to grow energy crops, such as sugar beet, which grows well in Denmark. In this article the options of adding sugar beet and straw to manure for co-digestion are evaluated.

The literature dealing with optimization of supply chains for biofuels has been studied in several literature papers (An et al., 2011; Ba et al., 2016; De Meyer et al., 2014; Iakovou et al., 2010; Sharma et al., 2013). The literature can be split into two main focus areas: models focused on optimization of the supply chains for one plant (Akhtari et al., 2014; Chen \& Fan, 2012; Shabani \& Sowlati, 2013), and models focused on optimization of the supply chain in a region with multiple plants (Huang et al., 2010; De Meyer et al., 2015; Ekşioğlu et al., 2009). 
Only few papers include a decision on output energy mode, e.g. (Börjesson \& Ahlgren, 2012), or the timing of storages for obtaining the best price of energy or satisfying a specific demand, e.g. (Huang et al., 2014). However, to our knowledge there are no papers addressing the optimal sizing of heat and biogas storages as well as output energy mode although optimal timing of production can lead to a higher income on the output side making plants more economically viable. Several articles concern modeling the supply of biomass to a bioenergy plant, e.g. (Eriksson \& Björheden, 1989; Shabani \& Sowlati, 2013; Zhang et al., 2013) but only in the article by Van Dyken et al. (2010) the losses in the energy value of the product are included. Furthermore of the papers reviewed, most papers include sizing of the plants as integer decisions (Gebreslassie et al., 2012; Kim et al., 2011).

The objective of this study is to model the supply chain of biogas production, where the supply chain is defined from farmer to the end market, in this case the heat, electricity and natural gas markets. The natural gas market is the natural gas grid, which can be utilized by upgrading biogas to biomethane. The modeling is done by finding the optimal flow of biomasses and biogas through a number of processes and deciding on which processes to invest in for a predefined location of the biogas plant. Furthermore, the model includes both the mass loss and the energy loss throughout the chain as well as a simple transport model.

The model seeks to find the optimal way of producing biogas such that the biogas plant projects become economically feasible by maximizing the profit. This will support the goal of producing more biogas in Denmark. The model can be used for evaluating different support schemes and their impact on the production of biogas. Moreover, the fairness of costs and required prices for each stakeholder can be evaluated as the prices of biomass and end products are decided between the stakeholders. An unfair distribution of profit, e.g. one stakeholder not earning anything, would not result in a biogas project. Last, the model can be used on existing facilities to optimally plan the production when used with exogenously given plant capacities. The stakeholder extension and the production planning will not been further addressed in this paper.

The paper is organized as follows: In the following Section 2 we give an overview of the value chain at the biogas plant, and introduce a network formulation of the problem. The model makes use of a time-place network on the output side, and a time-place-energy network on the input side. In Section 3 we use the constructed network to state the objective function of the problem and 
define constraints on the input and output side. Moreover, we model the transportation costs of collecting manure or crops as a number of concentric circles around the plant. Finally, in Section 4 we use the developed model to analyze the construction of a specific plant in Denmark, and discuss the results in Section 5. The paper is briefly concluded in Section 6 and future challenges are discussed.

\section{Problem statement}

The biogas supply chain is defined as the processes from farmer to energy demand. Figure 1 gives an overview of the supply chain used in the model. Manure or other biomass types, e.g. crops, waste or waste water, are the input to the model. Each arrow illustrates transport of either biomass, biogas or digestate. The inputs can go through storage - denoted by the small circles - pretreatment and storage again before arriving to the biogas plant. Here the anaerobic digestion takes place and the result is biogas and digestate. The digestate can go to a storage facility and then back to the livestock keepers or be sold elsewhere. The biogas goes through biogas storage and can from here either be: upgraded through water scrubbing, organic physical scrubbing, pressure swing absorption, or chemical scrubbing and sold as biomethane on the natural gas grid; upgraded through chemical methanation, where hydrogen is added to the biogas, and be sold on the natural gas grid and as heat; used in a boiler for heat production; or be used directly for combined heat-and-power (CHP) production, see also section 4.

The problem is to find the optimal way through the supply chain from the farmer to the energy demand, e.g. deciding how much of each input should be applied depending on transportation costs etc., what pretreatment type should be used, what type of energy the biogas should be used for etc. The planning horizon is one year and investment costs have been annualized.

The model uses different time scales on the input and output side. This is due to the fact that electricity prices vary on an hourly basis whereas biomass input is neither possible nor relevant to estimate on such a short time scale. To capture the seasonal variation of the biomasses, the input side is on a weekly basis, meaning that the available amount is registered for each week of the year.

On the input side, the model must keep track of both the mass and the energy content of the input. The mass is needed for sizing of the processes and amount of digestate, while the energy content must be used for calculating the biogas yield for the output side. Biomass can lose energy 


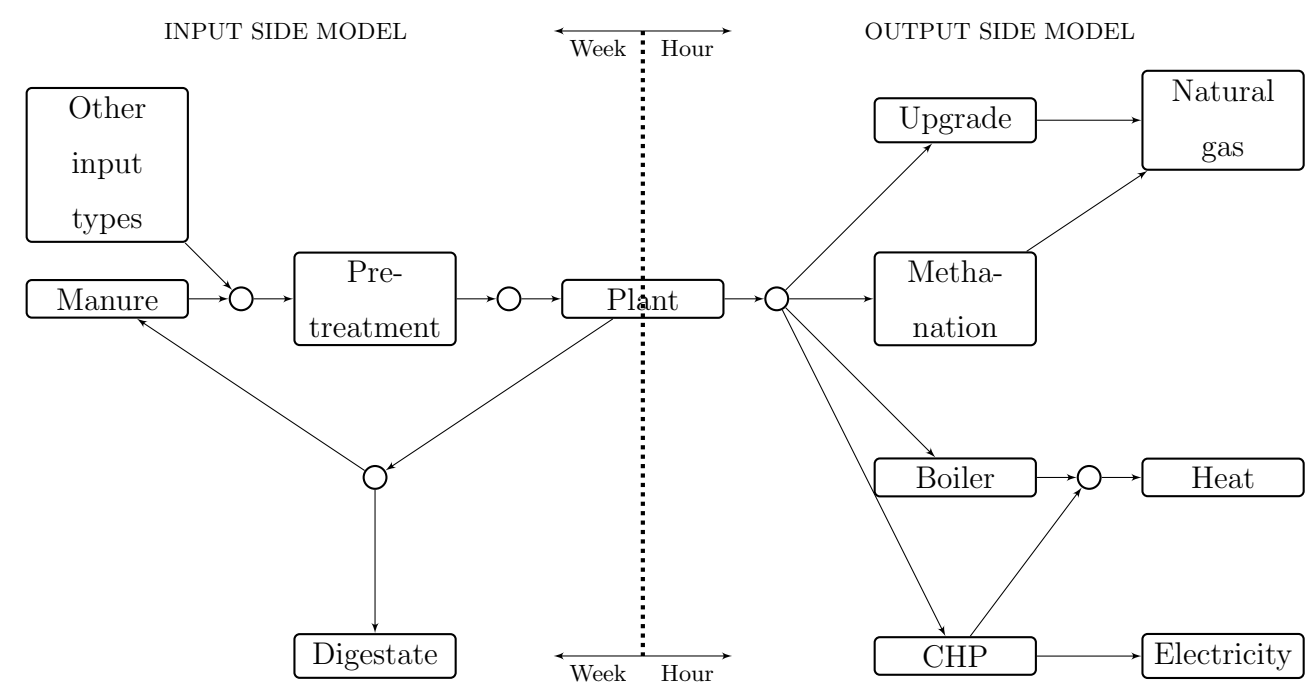

Figure 1: The biogas value chain from farmer to energy demand with the input side using a weekly time scale and the output side using an hourly time scale.

content as well as mass because of degradation of the biomass. For some processes the energy content might increase because of an increased digestability while the mass changes at another rate. On the output side, it is on the other hand only necessary to keep track of the amount of $\mathrm{m}^{3}$ biogas available as the heating value is assumed constant.

The supply chain is specified for the input and output side. Each side can be explained by using a number of processes $\mathcal{P}$ and $\overline{\mathcal{P}}$, and over the set of time periods $\mathcal{T}$ and $\overline{\mathcal{T}}$, where an overline is for the sets on the output side. Further, the input side uses the energy content $\mathcal{E}$ of each input type $\mathcal{I}$. All nomenclature is given in Appendix A.

\subsection{Network formulation}

The problem is solved using a network flow model in a (time, process, energy content)-space on the input side and in a (time, process)-space on the output side. A small example of a (time, process)-space graph is shown in figure 2. The graph on the input side, $\mathcal{G}(\mathcal{V}, \mathcal{A})$, is therefore described by the vertex set $\mathcal{V}$ and the $\operatorname{arc} \operatorname{set} \mathcal{A}$. An input side vertex $v \in \mathcal{V}$ is defined as the tuple $v=(i, p, t, e) \in(\mathcal{I} \times \mathcal{P} \times \mathcal{T} \times \mathcal{E})$.

On the output side, the graph, $\mathcal{G}(\overline{\mathcal{V}}, \overline{\mathcal{A}})$, is described by the vertex set $\overline{\mathcal{V}}$ and the arc set $\overline{\mathcal{A}}$. Last, the output side vertex $v \in \overline{\mathcal{V}}$ is defined as the tuple $v=(p, t) \in(\overline{\mathcal{P}} \times \overline{\mathcal{T}})$.

The definition of processes can be extended to include the placement in the chain. The farmers are in the process set $\mathcal{P}^{F}$. The plant on the input side are in the process set $\mathcal{P}^{P}$, and on the output 


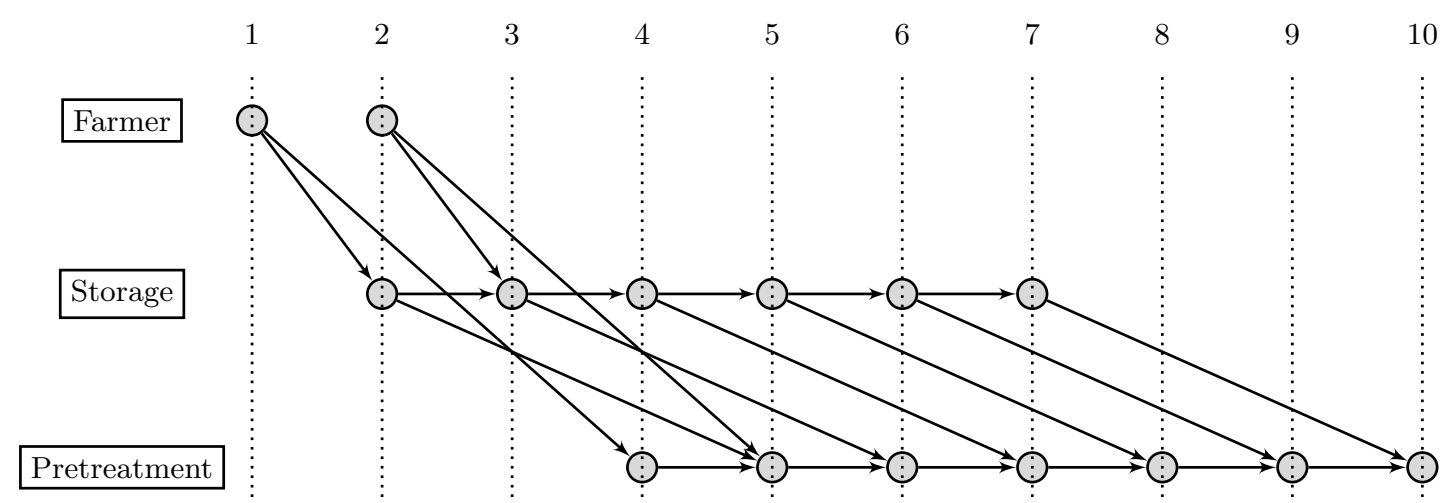

Figure 2: Example of a network in a (time,process)-space where the time periods are shown in the top and the process names on the left. The arcs going from vertex (time 1, farmer) to (time 2 , storage) are possible routes for the biomass to take from the farmer to a storage facility.

side in $\overline{\mathcal{P}}^{P}$. Natural gas, heat and electricity are in the process set $\overline{\mathcal{P}}^{E}$. Between the farmers and the plant on the input side are the inner processes contained in the set $\mathcal{P}^{I}$. On the output side the inner processes, $\overline{\mathcal{P}}^{I}$, are between the plant and the end use. The used superscripts are also used for the vertices for the processes.

For the arcs $a$ in the network, $\mathcal{A}^{-}(v)$ and $\mathcal{A}^{+}(v)$ are the input arcs arriving at vertex $v$ and leaving vertex $v$, respectively. The $+/$ - and $v$ can be left out to state any arcs on the input side. Further, $\mathcal{A}\left(v^{\prime}, v\right)$ represents all arcs between vertex $v^{\prime}$ and vertex $v$. Equivalent sets are defined on the output side by adding an overline on $\mathcal{A}$.

Using this graph representation, the resulting problem is a variation of a minimum cost flow problem with node capacities (Ahuja et al., 1993). For the input side, it is also a multi-commodity flow problem but this is handled by only generating arcs for the relevant biomasses, such that each biomass type has its own set of arcs and the biomasses only meet in the biogas plant.

\section{Mathematical formulation}

The model formulation is formulated based on the constructed network and is given in the following sections.

\subsection{Objective function}

The objective of the model is to maximize profit while satisfying the constraints described below. In the objective function the following variables are used. The flow on an arc $a \in \mathcal{A}$ and 
$a \in \overline{\mathcal{A}}$ is given by the variables $x_{a}$ and $\bar{x}_{a}$ for the input side and output side, respectively. The variable $x_{p, t}^{\text {left }}$ describes the amount of energy that cannot be sold due to a lack of demand from process $p$ in time $t$. This amount is explained further in subsection 3.4. The capacity of a process $p$ for input type $i$ is given by $k_{i, p}$ and $\bar{k}_{p}$.

For the biogas plant, economy of scale is modeled by making the cost curves for OPEX and CAPEX into piece-wise linear functions. The set of breakpoints between each linear segment is denoted $\mathcal{N}$. The variables, $x_{n}^{S O S 2}$ and $k_{n}^{S O S 2}$, describe the flow into the plant and the capacity of the plant. These are both special ordered set 2 (SOS2) variables and can obtain values between 0 and 1 , where at most two consecutive variables can obtain a non-zero value. The non-zero variables describe where the optimal solution is found on the linear segment between them (Beale \& Tomlin, 1970).

The transportation cost curve, described in section 3.5, is a piece-wise linear function and consists of a set of segments $\mathcal{M}$. The variable $x_{i, m}^{\text {trans }}$ describes the flow of each input type $i$ transported on each segment $m \in \mathcal{M}$ of the transportation cost curve. The variable $x_{m}^{\text {trans, xdig }}$ is the amount of extra digestate that must be transported to farmers not delivering manure.

The objective function can be formulated as:

$$
\begin{aligned}
& \max \sum_{v \in \mathcal{V}^{P}} \sum_{a \in \mathcal{A}^{-}(v)} x_{a} \eta^{\text {plant }} \rho^{\text {dig }}
\end{aligned}
$$

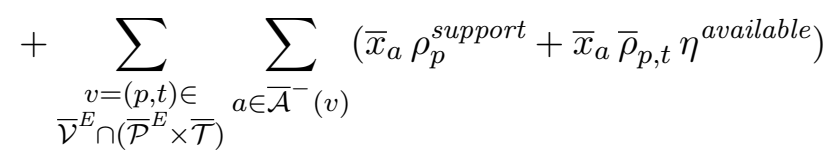

$$
\begin{aligned}
& -\sum_{p \in \overline{\mathcal{P}}} \sum_{t \in \overline{\mathcal{T}}} x_{p, t}^{\text {left }} \bar{\rho}_{p, t} \eta^{\text {available }} \\
& -\sum_{\substack{v=(i, p, t, e) \in \\
\mathcal{V}^{F} \cap\left(\mathcal{I} \times \mathcal{P}^{F} \times \mathcal{T} \times \mathcal{E}\right)}} \sum_{a \in \mathcal{A}^{+}(v)} x_{a} c_{i}^{\text {prod }} \\
& -\sum_{\substack{v=(i, p, t, e) \in \\
\mathcal{V} \cap(\mathcal{I} \times \mathcal{P} \times \mathcal{T} \times \mathcal{E})}} \sum_{a \in \mathcal{A}^{-}(v)} x_{a}\left(c_{i, p}^{O P E X}+c_{i, p, t}^{O P E X, v a r}\right) \\
& -\sum_{\substack{v=(p, t) \in \\
\overline{\mathcal{V}} \cap(\overline{\mathcal{P}} \times \overline{\mathcal{T}})}} \sum_{a \in \overline{\mathcal{A}}^{-}(v)} \bar{x}_{a} \bar{c}_{p}^{O P E X} \\
& -\sum_{i \in \mathcal{I}} \sum_{p \in \mathcal{P}} k_{i, p} \frac{T}{t_{i, p}^{\min }} c_{i, p}^{C A P E X}-\sum_{p \in \overline{\mathcal{P}}} \bar{k}_{p} \bar{c}_{p}^{C A P E X}
\end{aligned}
$$




$$
\begin{aligned}
& -\sum_{n \in \mathcal{N}} x_{n}^{S O S 2} c_{n}^{O P E X, S O S 2}-\sum_{n \in \mathcal{N}} k_{n}^{S O S 2} c_{n}^{C A P E X, S O S 2} \\
& -\sum_{i \in \mathcal{I}} \sum_{m \in \mathcal{M}} x_{i, m}^{\text {trans }} c_{i, m}^{\text {TRANS }}-\sum_{m \in \mathcal{M}} x_{m}^{\text {trans,xdig }} c_{m}^{\text {TRANS, xdig }} \\
& -\sum_{v \in \mathcal{V}^{P}} \sum_{a \in \mathcal{A}^{-}(v)} x_{a} \eta^{\text {plant }} c^{\text {HANDLING, dig }}
\end{aligned}
$$

Expressions (1a)-(1c) give the income which comes from selling digestate and biogas, and support for producing upgraded biogas, where $\rho^{\text {dig }}, \bar{\rho}_{p, t}$, and $\rho_{p}^{\text {support }}$ are prices and support obtained, $\eta^{\text {plant }}$

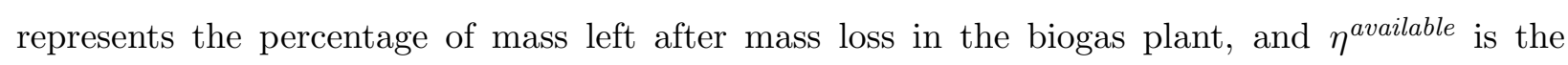
percentage of biogas that is not flared. This percentage is fixed and represents the anticipated amount that must be flared due to operational or maintenance reasons. $x_{p, t}^{\text {left }}$ is deducted from the flow to reflect what can be sold. The remaining expressions are the costs: (1d) is the cost of buying biomass, (1e)-(1g) are the operational expenditures (OPEX) and capital expenditures (CAPEX) on the input and output side, (1h) is the OPEX and CAPEX for the biogas plant, and (1i)-(1j) are the transportation and handling costs of biomass and digestate. The costs for each of these equations are given by the parameters: $c_{i}^{\text {prod }}$ is the production cost of input type $i ; c_{i, p}^{O P E X}$ and $\bar{c}_{p}^{O P E X}$ are the OPEX of input and output processes; $c_{i, p}^{C A P E X}$ and $\bar{c}_{p}^{C A P E X}$ are the CAPEX of input and output processes; $c_{n}^{O P E X, S O S 2}$ and $c_{n}^{C A P E X, S O S 2}$ are OPEX and CAPEX of the biogas plant in each breakpoint $n ; c_{i, m}^{\text {trans }}$ and $c_{m}^{T R A N S, x d i g}$ are the transportation cost of biomasses and digestate;

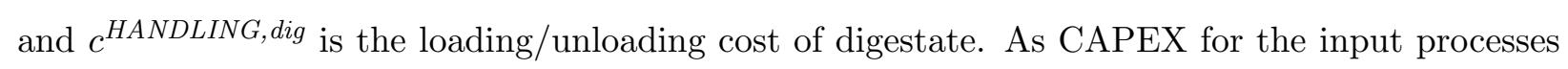
is given on an annual basis (tonnes/year), the capacity has to be scaled to match this. This is done by multiplying with the length of the year in weeks $T$ and divide by the minimum process time $t_{i, p}^{\text {min }}$ because the capacity is based on the required process time. An example is the biogas plant, where a capacity of 5769 tonnes with a minimum process time of three weeks is the same as a capacity of 100, 000 tonnes/year.

\subsection{Constraints on the input and output side}

Both the input and the output side share the same type of constraints. For simplicity, the same type of constraints are only shown for the input side sets but the full model can be seen in Appendix B and nomenclature in Appendix A. The constraints are:

$$
\sum_{\substack{v^{\prime}=\left(i^{\prime}, p^{\prime}, t^{\prime}, e^{\prime}\right) \in \mathcal{L} \\ \mathcal{V} \cap(\mathcal{I} \times \mathcal{P} \times \mathcal{T} \times \mathcal{E})}} \sum_{a \in \mathcal{A}\left(v^{\prime}, v\right)} x_{a} \eta_{i, p^{\prime}, p}=\sum_{a \in \mathcal{A}^{+}(v)} x_{a} \quad \forall v=(i, p, t, e) \in \mathcal{V}^{I} \cap\left(\mathcal{I} \times \mathcal{P}^{I} \times \mathcal{T} \times \mathcal{E}\right)
$$




$$
\begin{aligned}
& \sum_{\substack{v^{\prime}=\left(i, p^{\prime}, t^{\prime}, e^{\prime}\right) \in \\
\mathcal{V} \cap(\mathcal{P} \times \mathcal{T} \times \mathcal{E}) \mid p \neq p^{\prime}}} \sum_{a \in \mathcal{A}\left(v^{\prime}, v\right)} x_{a} \eta_{i, p^{\prime}, p} \leq \sum_{\substack{v^{\prime \prime}=\left(i, p^{\prime \prime}, t^{\prime \prime}, e^{\prime \prime}\right) \in \in \\
\mathcal{V} \cap(\mathcal{P} \times \mathcal{T} \times \mathcal{E}) \mid p \neq p^{\prime \prime}}} \sum_{a \in \mathcal{A}_{p r o c}\left(v, v^{\prime \prime}\right)} \frac{x_{a}}{\left(\eta_{i, p, p}\right)^{t^{\prime \prime}-t}} \\
& \forall v=(i, p, t, e) \in \mathcal{V}^{I} \cap\left(\mathcal{I} \times \mathcal{P}^{I} \times \mathcal{T} \times \mathcal{E}\right) \\
& \sum_{v=(i, p, t, e) \in \mathcal{V} \cap \mathcal{E}} \sum_{a \in \mathcal{A}^{-}(v)} x_{a}+\sum_{v=(i, p, t, e) \in \mathcal{V} \cap \mathcal{E}} \sum_{a \in \mathcal{A}_{\text {cap }}^{-}(v)} x_{a} \leq k_{i, p} \quad \forall(i, p, t) \in \mathcal{I} \times \mathcal{P} \times \mathcal{T}
\end{aligned}
$$

Constraint (2) ensures flow conservation in all processes where $\eta_{i, p^{\prime}, p}$ is the percentage of mass left after process $p$.

In order to solve the problem of minimum process time, the (time, process, energy content)graph for the input side and the (time, process)-graph for the output side are constructed such that the arrival time in a process includes the minimum process time of the process. The related constraint is (3), where a constraint is written for each vertex not being the first or last in the chain. The left hand side represents the flow to the vertex including the mass loss. The right hand side includes all arcs that leave the process within the given maximum process time, $\mathcal{A}_{\text {proc }}\left(v, v^{\prime \prime}\right)$, with a loss of energy, and the division by $\left(\eta_{i, p, p}\right)^{t^{\prime \prime}-t}$ represents the percentage of mass left in time $t^{\prime \prime}$. In figure 3 , an example of the process arcs are shown. The red arc, corresponding to the set $\mathcal{A}\left(v^{\prime}, v\right)$, describes the flow to the process with a minimum process time of 1 week - the minimum process time is included in the arrival time of the red arc - and a maximum process time of 5 weeks. The blue arcs indicate that the input in time period 3 must leave the process again before time period 7, corresponding to the set $\mathcal{A}_{\text {proc }}\left(v, v^{\prime \prime}\right)$.

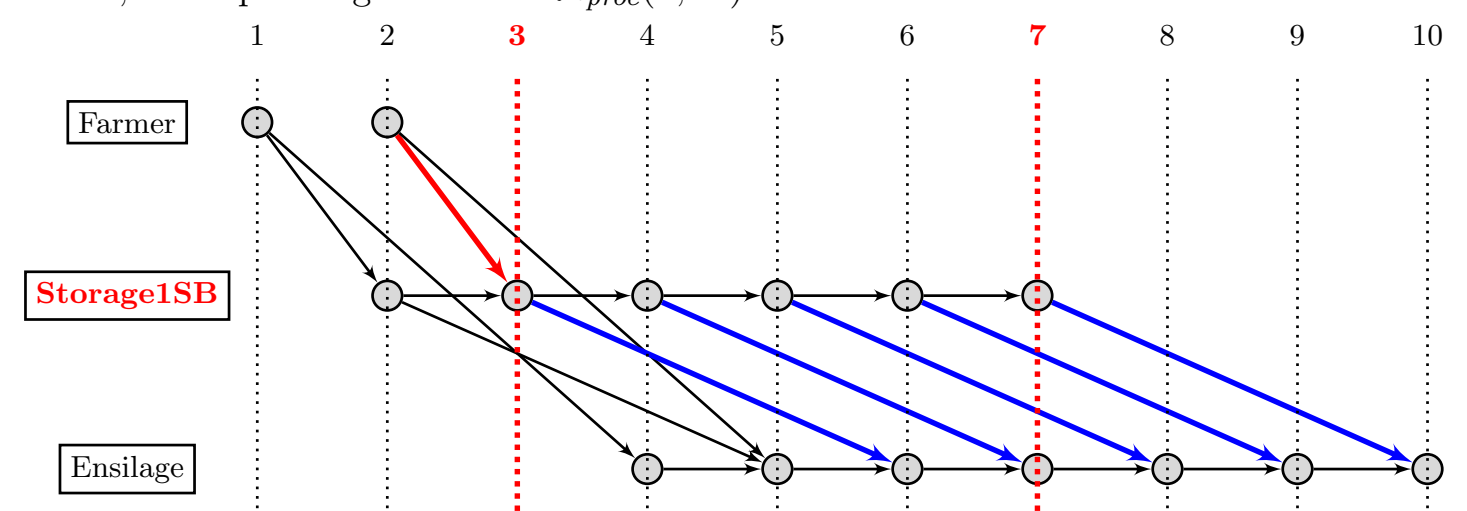

Figure 3: Example of the process time constraints' related arcs, showing a process with a minimum process time of 1 week and a maximum process time of 5 weeks

Constraint (4) sets the capacity of the processes. Because of the structure of the graph, the capacity must be larger than the mass currently in the process as well as the mass on the way to 
the process. The set $\mathcal{A}_{c a p}^{-}(v)$ represents the incoming arcs that arrive in vertex $v$ such that they are in the process at time $t$. An example of this is shown in figure 4 where the blue arcs represents the capacity set $\mathcal{A}_{\text {cap }}^{-}(v)$ and the red arc the set $\mathcal{A}^{-}(v)$.

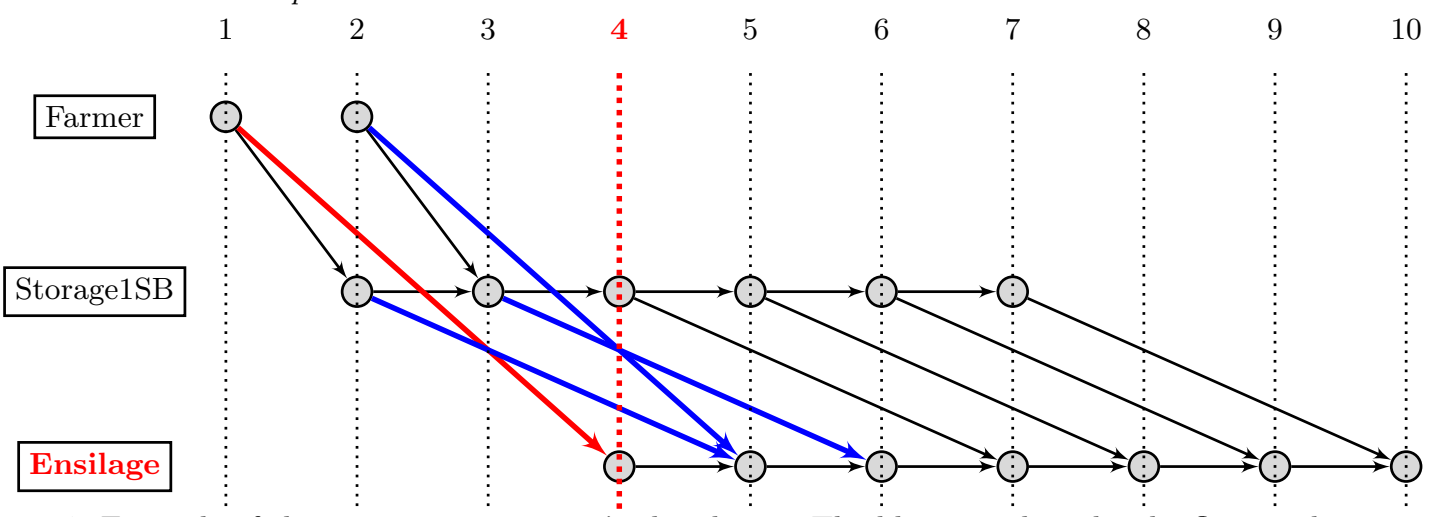

Figure 4: Example of the capacity constraints' related arcs. The blue arcs describe the flow to the process that are included in the capacity in time 4

\subsection{Input specific constraints}

An input constraint must be added to assure, that the available input of each type is not exceeded:

$$
\sum_{a \in \mathcal{A}^{+}(v)} x_{a} \leq b_{i, t} \quad \forall v=(i, p, t, e) \in \mathcal{V}^{F} \cap\left(\mathcal{I} \times \mathcal{P}^{F} \times \mathcal{T} \times \mathcal{E}\right)
$$

Where $b_{i, t}$ is the amount of biomass $i$ available in time $t$.

At the biogas plant, there are regulations on percentage of e.g. energy crops in input mix, here denoted as the subset $\mathcal{I}^{E C}$ with the percentage given as $\eta^{E C}$. The constraints can be formulated as:

$$
\sum_{\substack{v=(i, p, t, e) \in \\ \mathcal{V}^{P} \cap\left(\mathcal{I}^{E C} \times \mathcal{P}^{P} \times \mathcal{E}\right)}} \sum_{\substack{a \in \mathcal{A}^{-}(v) \\ x_{a}}} x_{a} \eta^{E C} \sum_{\substack{v=(i, p, t, e) \in \mathcal{V}^{P} \\ \cap\left(\mathcal{I} \times \mathcal{P}^{P} \times \mathcal{E}\right)}} \sum_{a \in \mathcal{A}^{-}(v)} x_{a} \quad \forall t \in \mathcal{T}
$$

OPEX and CAPEX for the biogas plant are implemented as stepwise linear functions. The resulting cost functions are concave and as they should be deducted from the income, it results in convex functions in the objective function that should be implemented using SOS2-variables. The related constraints are:

$$
\sum_{v \in \mathcal{V}^{P}} \sum_{a \in \mathcal{A}^{-}(v)} x_{a}=\sum_{n \in \mathcal{N}} b_{n}^{\text {plant }} x_{n}^{S O S 2}
$$




$$
\begin{aligned}
& \sum_{n \in \mathcal{N}} x_{n}^{\text {SOS2 }}=1 \\
& \sum_{n \in \mathcal{N}} b_{n}^{\text {plant }} k_{n}^{\text {SOS2 }}=\sum_{i \in \mathcal{I}} \sum_{p \in \mathcal{P}^{P}} \frac{T}{t_{i, p}^{\text {min }}} k_{i, p} \\
& \sum_{n \in \mathcal{N}} k_{n}^{\text {SOS2 }}=1 \\
& b_{1}^{\text {plant }} \leq \sum_{i \in \mathcal{I}} \sum_{p \in \mathcal{P}^{P}} \frac{T}{t_{i, p}^{\text {min }}} k_{i, p} \leq b_{\text {end }}^{\text {plant }}
\end{aligned}
$$

The first two equations set the $x_{n}^{S O S 2}$-variable by using the size of the biogas plant, $b_{n}^{\text {plant }}$ in each breakpoint $n$. Equations (9)-(11) set the capacity of the plant and ensure that $k_{n}^{S O S 2}$ is an SOS2variable, within the given boundaries of the cost function as given by the breakpoints $b_{1}$ and $b_{\text {end }}$.

\subsection{Output specific constraints}

The following constraint must be added to set the available input of biogas in each hour for each week based on the output from the biogas plant:

$$
\sum_{\substack{v=(p, t) \in \\ \overline{\mathcal{V}}^{P} \cap \overline{\mathcal{P}}^{P}}} \sum_{a \in \overline{\mathcal{A}}^{+}(v)} \bar{x}_{a}=\sum_{\substack{\left.v=\left(i, p, \frac{t}{\overline{7} \cdot 24}\right\rfloor+1, e\right) \\ \in \overline{\mathcal{V}}^{P} \cap\left(\mathcal{I} \times \overline{\mathcal{P}}^{P} \times \mathcal{E}\right)}} \sum_{a \in \mathcal{A}^{-}(v)} \frac{x_{a} \bar{\eta}_{i} e}{7 \cdot 24} \quad \forall t \in \overline{\mathcal{T}}
$$

Here the biogas yield of input type $i$ is denoted as $\bar{\eta}_{i}$. This is used to calculate the biogas yield by multiplying with the energy content of the biomass type when it ends in the plant. The constant $7 \cdot 24$ represents the number of hours per week and in the summation over $v$ on the right hand side the relation between hours and weeks is ensured.

Further, the capacity constraint must be changed to address the problem of sizing power and heat plants where the deciding size is on the output from the process. For CHP plants, the constraint is further complicated by the fact that it is only the power production deciding the size of the plant. For power and heat processes, $\mathcal{P}^{J}$, the following constraint must be satisfied:

$$
\sum_{a \in \overline{\mathcal{A}}_{\text {decide }}^{+}(v)} \bar{x}_{a} \leq \bar{k}_{p} \quad \forall v=(p, t) \in \overline{\mathcal{V}}^{J} \cap\left(\overline{\mathcal{P}}^{J} \times \overline{\mathcal{T}}\right)
$$

Where the set $\overline{\mathcal{A}}_{\text {decide }}^{+}(v)$ are the arcs from vertex $v$ determining the size of process $p$. For the rest of the processes on the output side, a capacity constraint equivalent to constraint (4) can be used. 
For CHP plants and methanation, the flow is also constrained by a fixed range between the two products from the process, i.e. heat and power, and heat and natural gas. This fixed range is implemented by the following constraint:

$$
\bar{x}_{a}=f_{p} \cdot \sum_{a^{\prime} \in \overline{\mathcal{A}}_{\text {extra }}^{+}(v)} \bar{x}_{a^{\prime}} \quad \forall v=(p, t) \in \overline{\mathcal{V}}^{K} \cap\left(\overline{\mathcal{P}}^{K} \times \mathcal{T}\right), a \in \overline{\mathcal{A}}_{\text {main }}^{+}(v)
$$

$\overline{\mathcal{A}}_{\text {main }}^{+}(v)$ is the set of arcs leaving process $p$ in time $t$ and arriving in a process that are of the main type, i.e. electricity for CHP and natural gas for methanation. $\overline{\mathcal{A}}_{\text {extra }}^{+}(v)$ is the set of arcs with origin in vertex $v$ but not of the main type. $f_{p}$ is the share of output going from process $p$ on the main arcs of all the output from process $p$. The set $\overline{\mathcal{P}}^{K}$ describes the set of processes that have the fixed range specified.

Last, there is a fixed amount of heat that can be sold in hour $t, d_{p, t}$, only defined for heat processes $\overline{\mathcal{P}}^{H}$. This amount is the heat demand in the area and restricts the flow to the heat process. However, the heat can always be cooled away so the following constraint describes how much heat that cannot be sold in each hour:

$$
\sum_{a \in \overline{\mathcal{A}}^{-}(v)} \bar{x}_{a} \leq d_{p, t}+x_{p, t}^{\text {left }} \quad \forall v=(p, t) \in \overline{\mathcal{V}}^{H} \cap\left(\overline{\mathcal{P}}^{H} \times \overline{\mathcal{T}}\right)
$$

\subsection{Transportation}

Because the transportation planning problem is an additional complex problem to solve, the transportation side of the problem is simplified as in (Boldrin et al., 2016). The procedure is to divide the area in which the plant lies into concentric circles with the plant in the center, see figure 5. This assumption can be used for areas with extensive and evenly distributed road networks. For each annulus - the region between two consecutive circles - the amount of biomasses is given and assumed equally spread out over the annulus. As shown in the objective function, there is a need to calculate the cost of collecting in each breakpoint, $n^{\prime}$. This $n^{\prime}$ corresponds to one of the radii shown in the figure.

To calculate the costs, the amount of biomass in the annulus between $n^{\prime}$ and $n^{\prime}-1, a m_{i, n^{\prime}}$, must be obtained. From this the average transportation distance, $\Delta d_{i, n^{\prime}}$, for the accumulated mass, $A M_{i, n^{\prime}}$, for the biomass type $i$ in breakpoint $n^{\prime}$ can be calculated by:

$$
\Delta d_{i, n^{\prime}}=\sum_{j=1}^{n^{\prime}} \frac{a m_{i j}}{A M_{i, n^{\prime}}} \cdot \Delta r_{j}
$$




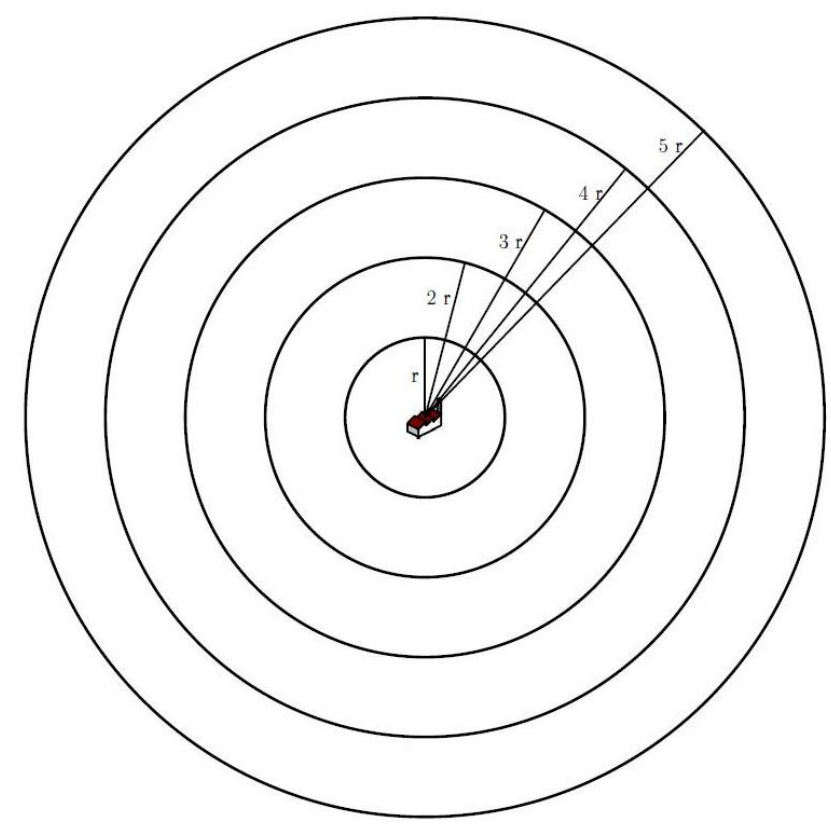

Figure 5: The concentric circles around the plant is used to simplify the problem of transportation. The area between two circles is the annulus.

Here $a m_{i j}$ denotes the mass that can be collected within the radius $r_{j}$ and $r_{j-1}$, and $\Delta r_{j}$ denotes the average distance from the given area to the plant. $\Delta r_{j}$ can be calculated by finding the average area, $\Delta A_{j}$, of the circles using the area of circle $j$ and $j-1$, denoted by $A_{j}$ and $A_{j-1}$ :

$$
\Delta A_{j}=\frac{A_{j}+A_{j-1}}{2}
$$

Which can be reduced to:

$$
\pi \Delta r_{j}^{2}=\frac{\pi r_{j}^{2}+\pi r_{j-1}^{2}}{2}
$$

And finally:

$$
\Delta r_{j}=\sqrt{\frac{r_{j}^{2}+r_{j-1}^{2}}{2}}
$$

To use the Euclidean distance, 2-norm distance, from the midpoint to the average radius' endpoint in $2 \mathrm{D}$, seems to be a fair assumption as the road network in Denmark, where the case study is performed, is rather fine-meshed. In other countries it might be relevant to use distance measures like the Manhattan distance, or other distance measures.

The trucks used for transportation depends on the type of input. Therefore, the capacity, velocity and costs of each truck depend on the input type. The cost, $c_{i, n^{\prime}}^{T R A N S}$ of each biomass type 
transported to the plant in each breakpoint $n^{\prime}$ can be expressed by the following formula:

$$
c_{i, n^{\prime}}^{\text {TRANS }}=2 \cdot \frac{a m_{i, n^{\prime}} \Delta d_{i, n^{\prime}} c_{i}^{\text {truck }}}{k_{i}^{\text {truck }} v_{i}}+\frac{a m_{i, n^{\prime}}\left(t_{i}^{\text {load }} c_{i}^{\text {load }}+t_{i}^{\text {unload }} c_{i}^{\text {unload }}\right)}{k_{i}^{\text {truck }}}
$$

The first part of the right hand side is the transportation time to and from the farmer, hence the multiplication with 2. Here $c_{i}^{\text {truck }}$ is the hourly cost of transporting input type $i$ on the truck used for transportation, $k_{i}^{\text {truck }}$ is the capacity of the truck, and $v_{i}$ is the velocity of the truck. The second part is the amount of time it takes to load/unload the truck, $t_{i}^{\text {load }}$ and $t_{i}^{\text {unload }}$, times the cost of loading/unloading, $c_{i}^{\text {load }}$ and $c_{i}^{\text {unload }}$ depending on the type of machines that is to be used divided by the capacity of each load. This is an approximation to the real-life problem as we assume that the trucks only do full-load trips even though this most likely is not the case.

The cost can be used for the digestate as well, but considering that as much digestate as possible is delivered back to the livestock keepers, it is only a small amount that has to be sent elsewhere. The exact amount depends on the willingness of farmers to receive more than they delivered to the plant. The amount that can be sent to these places is also to be obtained and structured as above. However, the cost is different as the amount sent to the animal farmers is already taken care of in the first part of equation (20). The only thing that is missing is the loading/unloading of all digestate as well as the transportation to the new places. Transportation to the new places are found by:

$$
c_{n^{\prime}}^{\text {TRANS,xdig }}=2 \cdot \frac{a m_{n^{\prime}}^{\text {dig }} \Delta d_{n^{\prime}}^{\text {dig }} c^{\text {truck,dig }}}{k^{\text {truck,dig }} v^{\text {dig }}}
$$

Where the same notation as above is used but instead of an index $i$ the superscript dig is used to denote the digestate.

The handling costs are not depending on the amount available in each circle but can be expressed by:

$$
c^{\text {HANDLING,dig }}=\left(t^{\text {load,dig }} c^{\text {load,dig }}+t^{\text {unload,dig }} c^{\text {unload,dig }}\right)
$$

If the cost functions, $c_{i, n^{\prime}}^{T R A N S}$ and $c_{n^{\prime}}^{\text {TRANS,xdig }}$, are plotted, they are stepwise linear and convex function. As we are maximizing the negative functions, the terms are concave in the objective function and hence they can be modeled using linear variables. Therefore, the cost functions given above are recalculated to be the slope of the cost function in the interval $m$ by:

$$
c_{i, m}^{T R A N S}=\frac{c_{i n^{+}(m)}^{T R A N S}-c_{i n^{-}(m)}^{T R A N S}}{a m_{i n^{+}(m)}}
$$


Where $n^{-}(m) / n^{+}(m)$ denotes the breakpoints before and after $m$. This formula can also be used on $c_{n^{\prime}}^{\text {TRANS,xdig }}$ to get the cost for $c_{m}^{\text {TRANS,xdig }}$.

The constraints that must be added to the model related to transportation are:

$$
\begin{aligned}
\sum_{m \in \mathcal{M}} x_{i, m}^{\text {trans }}= & \sum_{\substack{v=(i, p, t, e) \in \\
\mathcal{V}^{T} \cap\left(\mathcal{P}^{T} \times \mathcal{T} \times \mathcal{E}\right)}} \sum_{a \in \mathcal{A}^{+}(v)} x_{a} \quad \forall i \in \mathcal{I} \\
& x_{i, m}^{\text {trans } \leq a m_{i, m}} \quad \forall i \in \mathcal{I}, m \in \mathcal{M}
\end{aligned}
$$

Where $\mathcal{V}^{T}$ are the vertices from which transportation are made as specified by the user.

For the digestate, the amount that cannot be sent back to the animal farmers is calculated in the model by:

$$
x\urcorner \text { manure } \geq \sum_{\substack{v=(i, p, t, e) \in \\ \mathcal{V}^{P} \cap\left(\mathcal{P}^{P} \times \mathcal{T} \times \mathcal{E}\right)}} \sum_{a \in \mathcal{A}^{-}(v)} x_{a} \eta^{\text {plant }}-\sum_{v \in \mathcal{V}^{M}} \sum_{a \in \mathcal{A}^{+}(v)} x_{a} \gamma
$$

Where $x^{\neg \text { manure }}$ is the amount that cannot be sent back to the manure suppliers and $\gamma$ represents the percentage of delivered manure that can be sent back. To find the amount that can be sent back on each segment, the following equations are used:

$$
\begin{array}{r}
x_{m}^{\text {trans }, x d i g} \leq a m_{m}^{\text {dig }} \quad \forall m \in \mathcal{M} \\
\sum_{m \in \mathcal{M}} x_{m}^{\text {trans }, x d i g} \leq x^{\neg \text { manure }}
\end{array}
$$

\section{Case study}

A small case study was conducted in order to evaluate straw, sugar beet, and pig manure as feedstock to the biogas plant. The case study is chosen to be as close to real-life as possible but is not intended to be replicating a planned plant as the extensive data needed cannot be gathered from a specific plant. North-West of Denmark is used as the placement. The data used is based on results on energy yields, mass losses, and cost estimates of pretreatment and transportation etc. from the BioChain project (Abildgaard, 2016), and economic data on current and future Danish biogas plants which have been used to make the cost curves for CAPEX and OPEX for the biogas plants $^{1}$.

\footnotetext{
${ }^{1}$ The data is based on economic data from Danish biogas plants to apply for financial aid from the Danish Energy Agency. An anonymized version of the costs can be found in (EA Energianalyse, 2014)
} 
The case study includes two pretreatment facilities for sugar beet, one pretreatment for straw, and no pretreatment for manure. It is assumed that the pretreatments are located at the biogas plant. The network on the input side is shown in figure 6 and the economic data for each process can be seen in table C.1 and C.2 in Appendix C. The transportation data can be seen in table C.3 also in Appendix C.

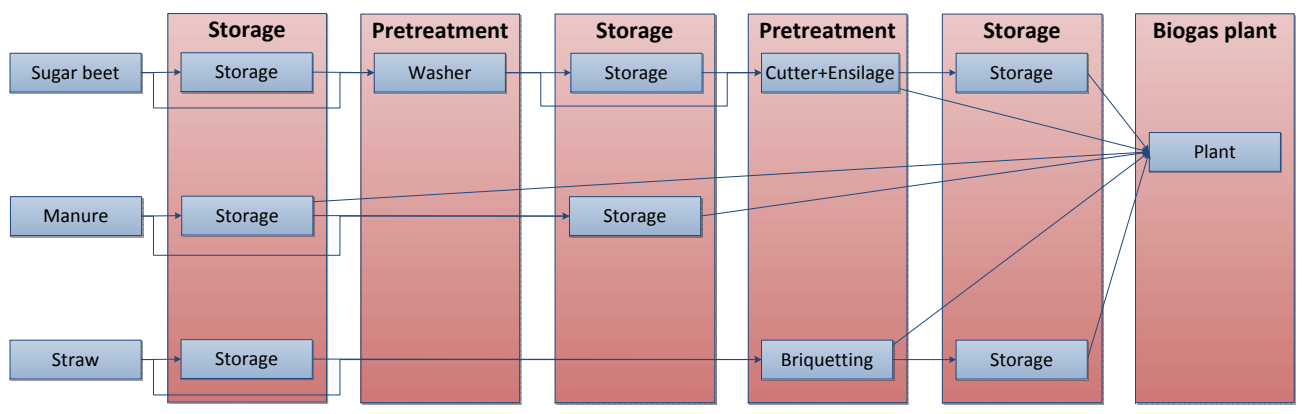

Figure 6: The network on the input side

The step-wise linear function of OPEX and CAPEX on the plant can be seen in figure 7. From this figure it is seen, that the minimum size of the plant is set to 100, 000 tonnes of input per year and the maximum size is set to 600,000 tonnes per year. The maximum size is set because of a lack of data for larger biogas plants.

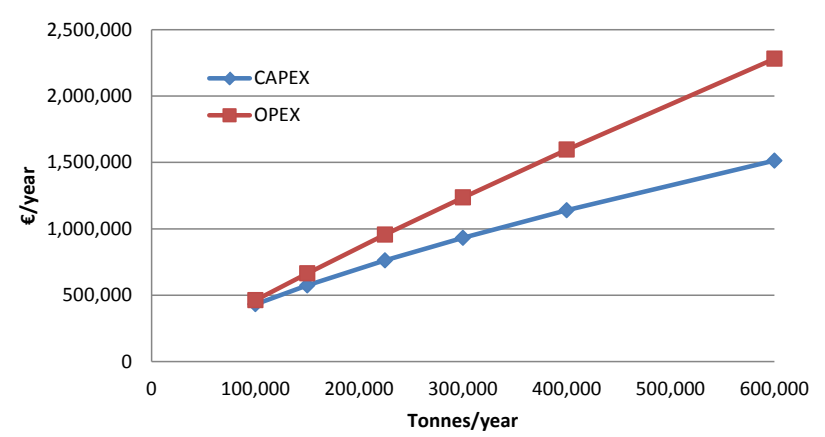

Figure 7: The step-wise linear functions of CAPEX and OPEX

The CAPEX, OPEX and efficiency data for the output processes, gathered from various sources, are listed in table C.4 in Appendix C. We have assumed that the cost of cooling the excess heat is included in the costs of CHP's, boiler, and methanation. The network used can be seen in figure 8 . In the network a transformation from $\mathrm{m}^{3}$ biogas to $\mathrm{m}^{3}$ natural gas or MWh is made such that the output in the demand is given in $\mathrm{m}^{3}$ natural gas for the NG distribution grid and in MWh for heat and electricity. In order to make this transformation from the upgrading process methanation, an 
extra process with no losses and no process time is inserted between methanation and heat storage to allow for two different units on the output. This process is called Nm3ToMWh. For the specific methanation type, there is no need for pressure regulation as the resulting biomethane will have a pressure of 40 bars, which is the pressure needed for injection into the distribution grid.

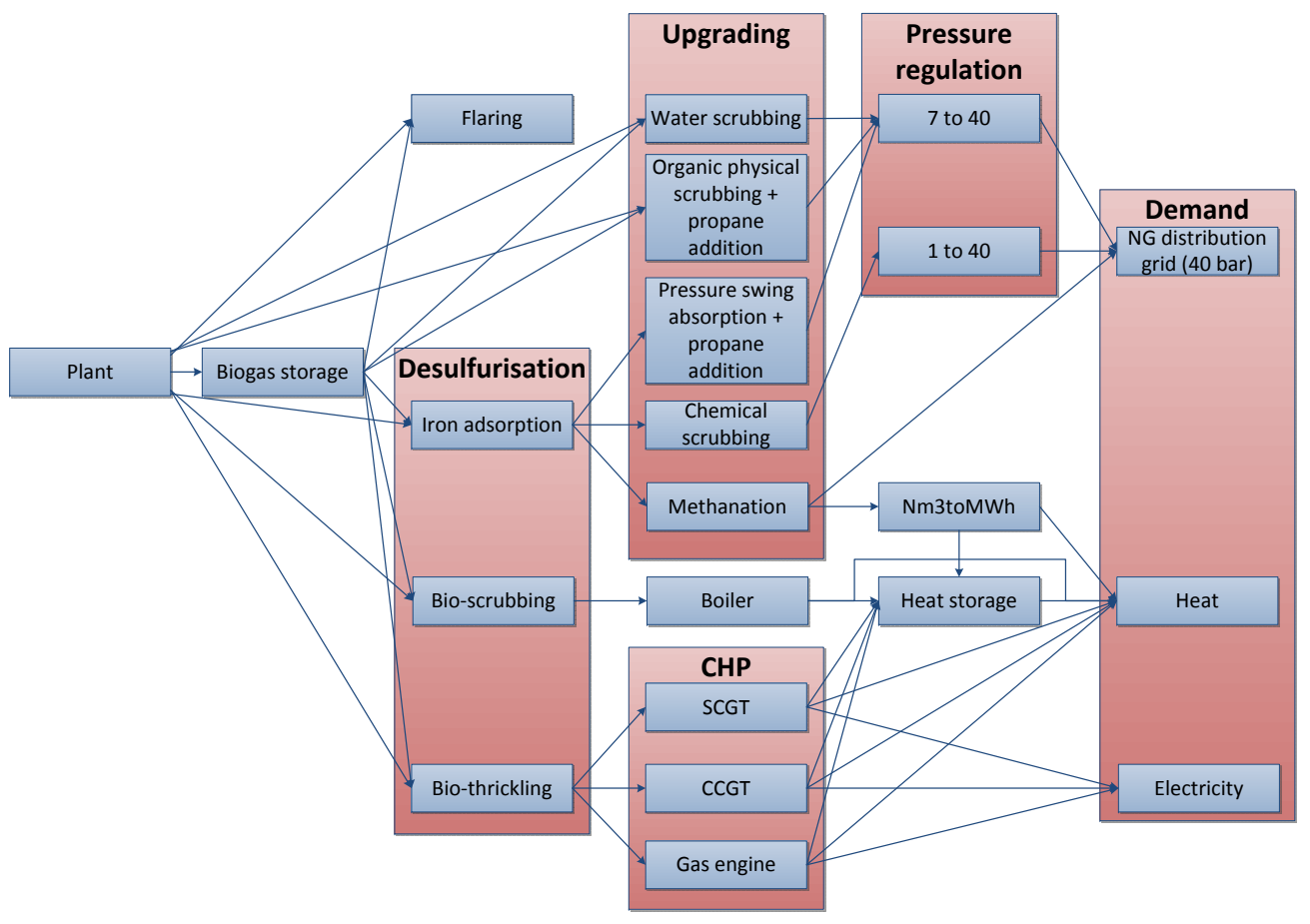

Figure 8: The network on the output side

In Denmark, biogas is state subsidized based on the end use of the biogas. Table 1 gives an overview of this support. The support scheme implies that the electricity price is fixed throughout

\begin{tabular}{l|c}
\hline \hline End use & Support \\
\hline Electricity & Fixed price of electricity: $163 € / \mathrm{Mwh}$ \\
Heat & No support \\
Natural gas & $0.64 € / \mathrm{Nm}^{3} \mathrm{NG}$ \\
\hline
\end{tabular}

Table 1: The Danish support scheme for biogas production

the year. However, for methanation which uses a lot of electricity to produce the natural gas, the electricity price is based on the price from 2015 in Western Denmark and is an hourly price. Furthermore, the upgraded biogas will earn both the support and the natural gas price. The exact support for the upgraded biogas through methanation is unknown as there are no operating biogas 
plants in Denmark using methanation. The argument for having subsidy on the upgraded gas is that it is a waste treatment of manure, however, when the methanation production is used, the outcome is more gas per input of biogas and thus an unfair amount of subsidy for methanation. An argument for keeping the subsidy for methanation at the same level as for the other upgrading technologies could be that there is an increased focus in Denmark on converting electricity to other fuels. Therefore, we assume that the methanation process will earn the same amount of subsidy. Due to lack of data, the natural gas price variations are based on the natural gas price for Denmark in 2013. To convert it into the price level of 2015, the prices from 2013 have been increased to achieve the average price of 2015. The natural gas price is a daily price. As given by the Danish regulation, the maximum amount of energy crops that can be used in the plant is $12 \%$ in order to achieve subsidies.

The methane percentage of the biogas is assumed to be $65 \%$ and the amount of flaring needed because of plant failures etc. is assumed to be $5 \%$. The assumed value of digestate is $8.84 € /$ ton (Birkmose et al., 2013), and the assumed mass passing through the biogas plant is $91.93 \%$ (Boldrin et al., 2016). This percentage is assumed constant as the most significant part of the input is water from the manure, even though the amount is dependent on the input mix and pretreatments used.

\section{Results and discussion}

The model has been implemented in GAMS-software, version 24.4 and was solved using CPLEXsolver, version 12.6, on a Dell Latitude E6430 with 2.4GHz CPU, 8GB RAM, and a Windows 7 Enterprise 64-bit operating system. The model has been solved using the Barrier algorithm in CPLEX as it showed to reduce the running time to less than half than by applying the default setting.

Because of the maximum size of the plant of 600,000 tonnes of input per year, the relaxed mixed integer programming (RMIP) problem finds integer solutions for many of the scenarios, i.e. solutions where the SOS2 variables are adjacent and at most two of the variables are non-zero. Therefore, all results have been found using the RMIP model and if the solution was not integer, the MIP was run. The RMIP runs can be performed within five minutes and a MIP run is in the worst-case done within 21 minutes.

The results of the data described in section 4 can be seen in table 2 . The table shows that the 
plant is only profitable because of the support, underlining the necessity of optimizing the supply chain. It is seen that the optimal way of producing is by building as large as possible and using manure and straw as input biomasses. The location of the plant determines the size of the plant so if the input biomasses were farther from the plant, the size would - at some point - decrease. The straw is pretreated before it is stored and used continuously over the year while the manure is used continuously over the year implying no investment in storage for the manure.

\begin{tabular}{l|cc}
\hline \hline Objective & $26,671,879$ & $€$ /year \\
Income, excluding support & $18,158,065$ & $€ /$ year \\
Support & $33,577,639$ & $€ /$ year \\
Cost & $25,063,825$ & $€ /$ year \\
Size of biogas plant & 600,000 & tonnes/year \\
Sugar beet & 0 & tonnes/year \\
Manure & 528,000 & tonnes/year \\
Straw & 72,000 & tonnes/year \\
Biomethane & $52,465,062$ & $m^{3}$ \\
Electricity & 0 & $\mathrm{MWh}$ \\
Heat & 36,017 & $\mathrm{MWh}$ \\
\hline
\end{tabular}

Table 2: Results of the model run

The straw is used continuously over the year at the limit of $12 \%$ at the plant, with a large storage after the pretreatment. This means that the cost of storage for straw is small when including the extra biogas yield it gives. The usage of straw throughout the year gives a constant output that must be handled by the output processes. The size of the processes on the output side can be seen in table 3 and here it shows that upgrading to biomethane using methanation is optimal, even though the heat demand is fully covered in some periods.

\begin{tabular}{l|cc}
\hline \hline Gas storage & 11,620 & $m^{3} B G$ \\
Iron adsorption & 3,981 & $m^{3} B G$ \\
Methanation & 3,981 & $m^{3} B G$ \\
Heat storage & 14.3 & $M W$ \\
\hline
\end{tabular}

Table 3: Capacities on the output processes for the model run

The heat storage is used to a small extent, corresponding to approximately 16 times the smallest 
heat demand or 2 times the largest heat demand, but this is not enough to cover the amount of heat produced, so a significant amount of heat is cooled off. The extra cost of the heat storage does not outweigh the extra support obtained due to the extra production of biomethane from methanation.

The sizes of the gas and heat storage indicate that the biogas can be utilized better by including the output side as the flexibility of the storage can be used. The graphs in figure 9 show the usage of the gas and heat storage in the first week of the modeling year together with the normalized electricity price. The natural gas price is not shown as it did not affect the usage of the biogas.

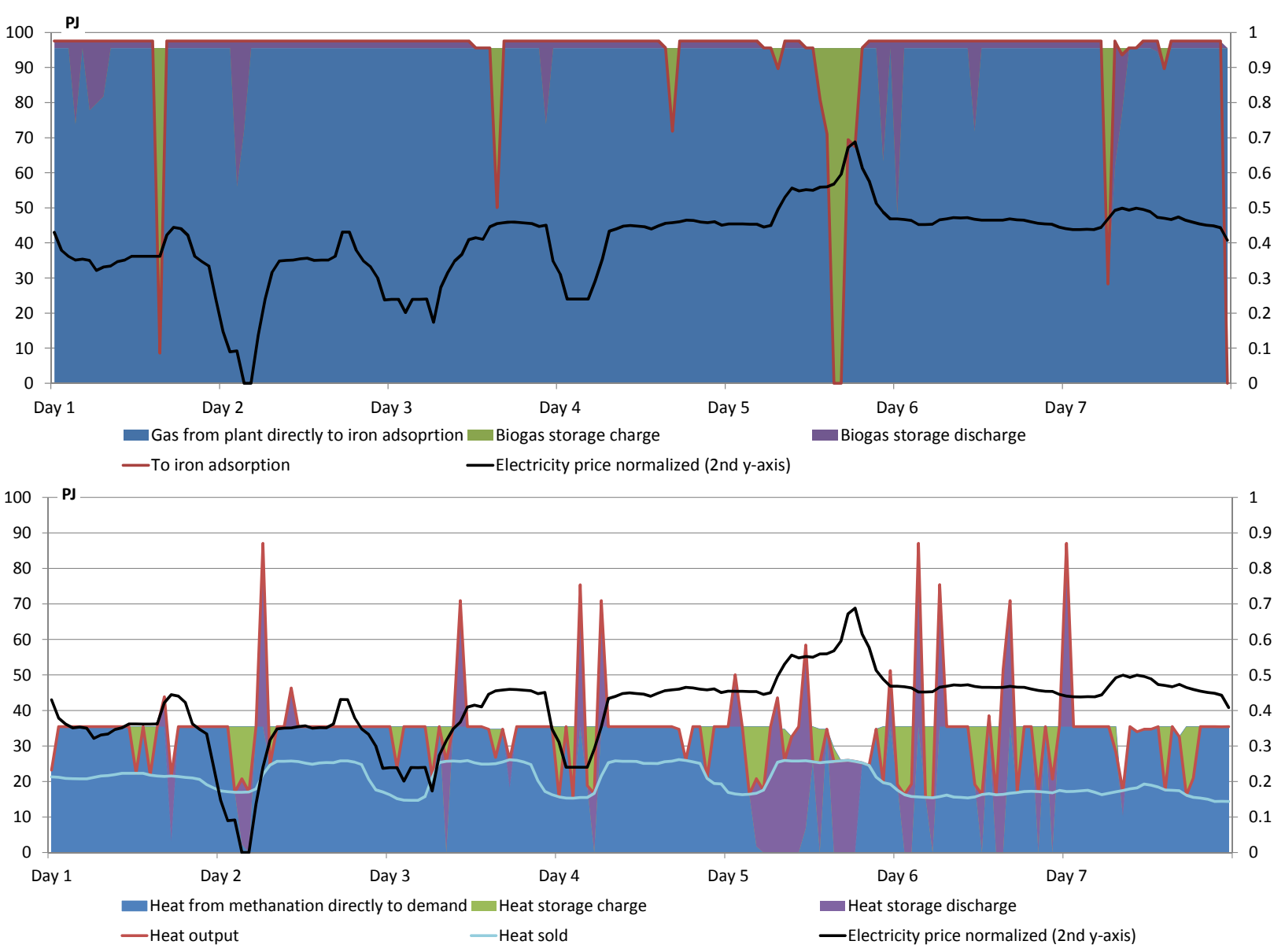

Figure 9: Usage of the gas and heat storage for the first week of the year. The top graph shows the gas storage usage and the graph below shows the heat storage usage.

For both graphs it can be seen that there is a reaction to an increase in electricity prices. For the gas storage the reaction is seen before the actual peak as there is a delay from the gas storage to 
the methanation. On the highest peak in day 5 it can be seen that the gas is stored in the gas storage while the heat, which was previously stored in the heat storage, is discharged to fulfill the heat demand. The gas storage is discharged most of the time to supply the methanation with more biogas whereas the heat storage is discharged more intensely in some periods, e.g. when there is no methanation taking place as in day 5. The many charges and discharges in the heat storage happens as there are no cost for charging or discharging, the OPEX for the storage is zero, and a lot of the heat generated has no value as it must be cooled off. The amount of heat cooled in each time step is the amount between the red and light blue line.

\subsection{Sensitivity analysis}

Because the total costs of each of the output processes are at a similar level, different scenarios related to the output data have been chosen to investigate the impact of changes. However, these scenarios have to affect the methanation process a lot as the difference between the methanation process and the second best solution is high. The chosen scenarios are shown in table 4 . The

\begin{tabular}{|c|c|c|c|c|}
\hline Scenario & Natural gas price & Electricity price & Heat demand & Subsidy, biomethane \\
\hline 1 & $50 \%$ & - & - & - \\
\hline 2 & - & $150 \%$ & - & - \\
\hline 3 & - & - & $50 \%$ & - \\
\hline 4 & $50 \%$ & $150 \%$ & $50 \%$ & - \\
\hline 5 & - & - & - & $50 \%$ \\
\hline 6 & $50 \%$ & - & - & $50 \%$ \\
\hline 7 & - & $150 \%$ & - & $50 \%$ \\
\hline 8 & - & - & $50 \%$ & $50 \%$ \\
\hline
\end{tabular}

Table 4: Scenarios used for the sensitivity analysis

result of scenario 1-4 can be seen in figure 10. As the first result shows that the model chooses to upgrade the biogas, the natural gas price might influence the solution such that another setting will be chosen if the natural gas price is decreased. To determine the effect, the natural gas price is decreased to $50 \%$. The methanation process is still the optimal way of producing even though the profit decreases. The decrease in the objective function value is approximately $20 \%$ and is due to the loss in the sales price of the biomethane.

For the electricity price, the methanation process might become too expensive if the electricity 


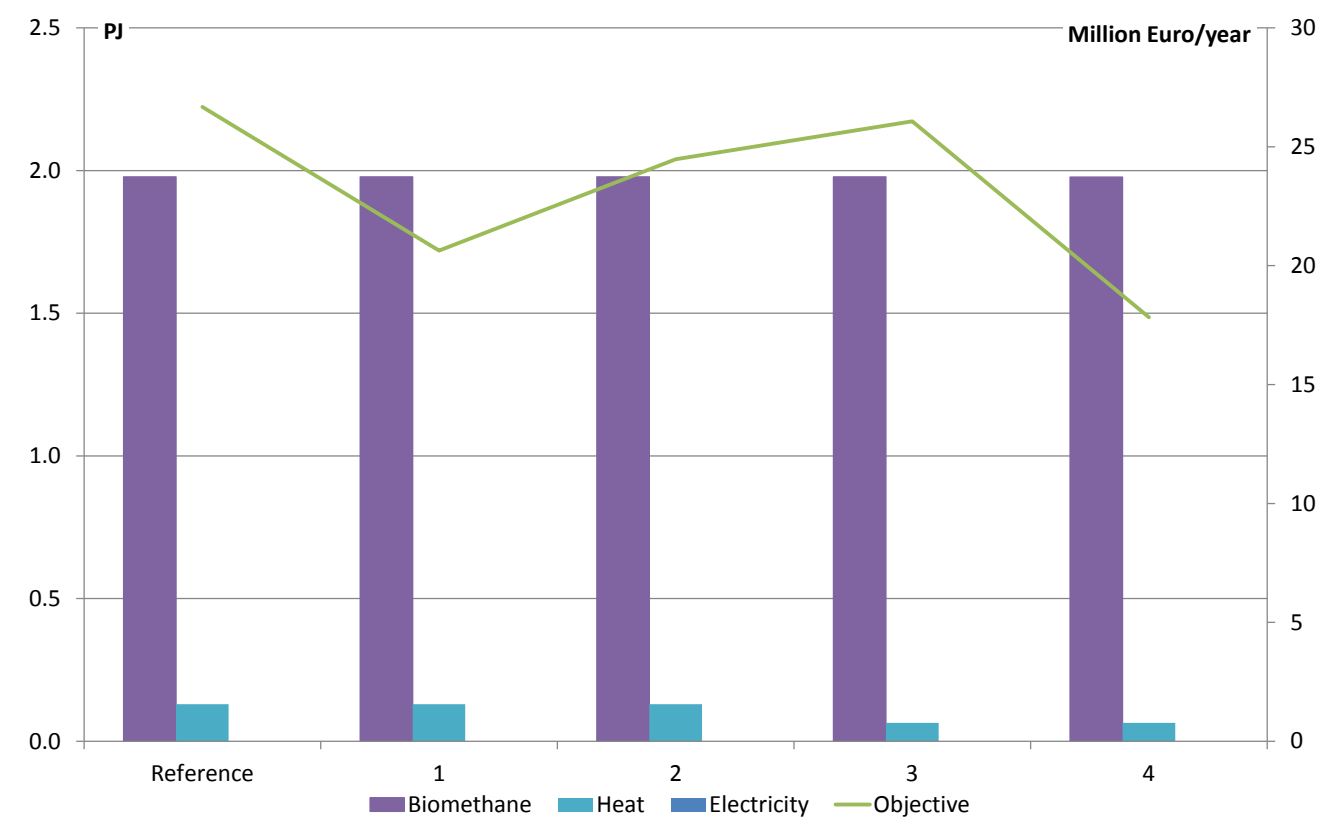

Figure 10: Results of scenarios 1 to 4 showing the biomethane, heat, and electricity production on the left axis and the objective function value on the right axis

price increase. Here the electricity price is increased to $150 \%$ to see if it affects the solution. The scenario shows that the solution is stable to changes in electricity prices as there is only a reduction of around $7 \%$ from the reference scenario. This can be explained by the low effect as it affects only the OPEX of methanation.

The heat demand in the region could be of interest. If the heat demand is decreased, methanation will not be used as much because the heat cannot be sold. The demand is decreased to $50 \%$ and from figure 10 it is seen that the objective function is close to the reference scenario. The change in heat demand only changes the amount that can be sold and as this amount adds a small income to the objective function, the objective function value is changed with only $2 \%$.

The combination with a decrease in natural gas price, an increase in electricity price, and a decrease in heat demand is used. The objective function value is affected by all changes and is now $29 \%$ less than in the reference scenario. This is still not enough to change the optimal investments and therefore the extra scenarios with a reduction in subsidy for biomethane are introduced.

Last, the subsidy for biomethane is set to $50 \%$ of the current support and is also combined with the regulation of natural gas price, electricity price and heat demand. The results can be seen in figure 11. Here it is seen that the only scenarios where the methanation process is not 


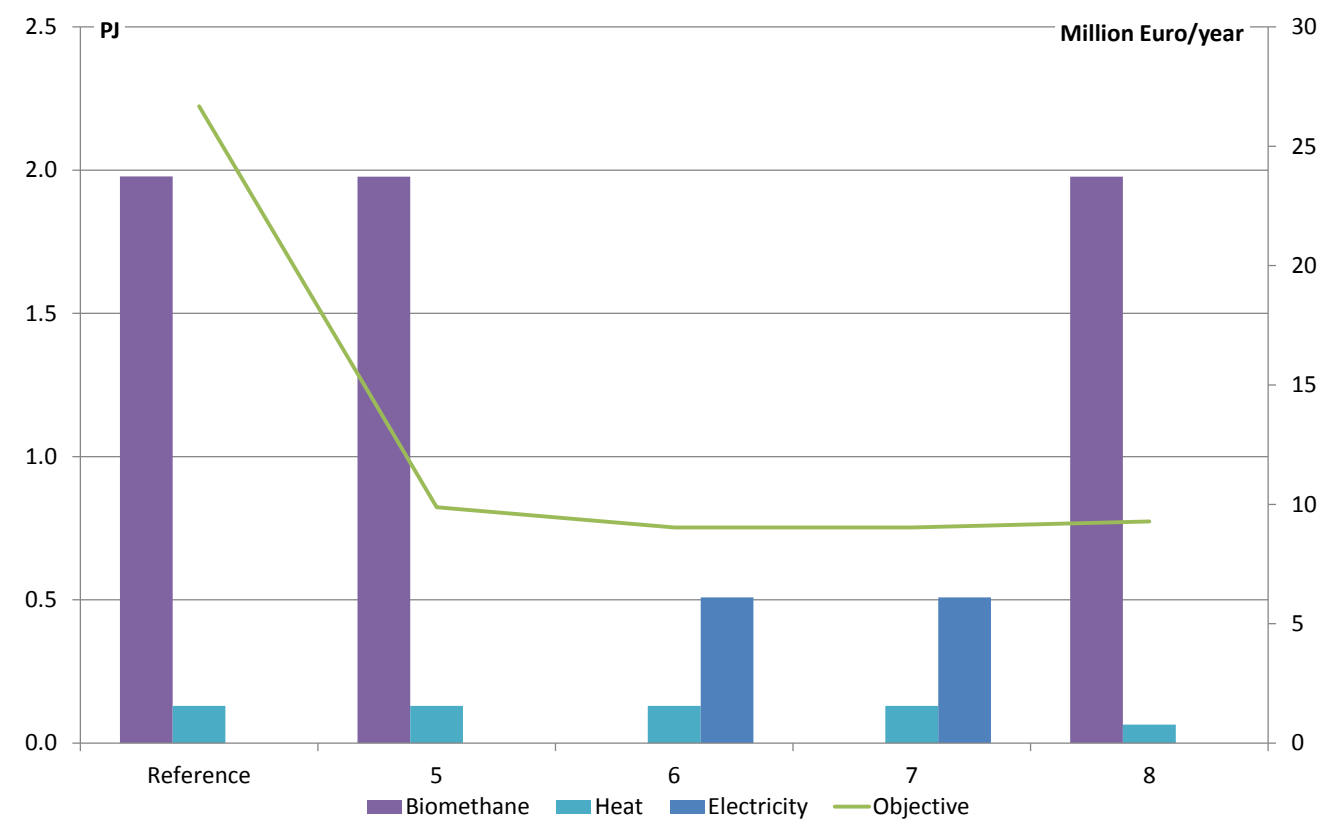

Figure 11: Results of scenarios 5 to 8 showing the biomethane, heat, and electricity production on the left axis and the objective function value on the right axis

used is when the subsidy decrease is combined with natural gas price reductions or an increase in electricity price, meaning that the production cost of methanation is getting more expensive. Further, the reduction of support as well as the combination with a decrease in heat demand gives a solution with an objective function value close to scenario 6 and 7 but with methanation as the best investment. This shows that given a decrease in support, the possible investments on the output side are more responsive to fluctuations in prices than when the support is not decreased.

\section{Conclusion}

Biogas and bioenergy projects in general have received growing attention the last years in order to make them profitable by optimizing the supply chain. However, the literature is mostly focused on the supply of biomasses to the plant and does not consider the possible gains of including storage possibilities on the output side.

In this article, a mathematical model optimizing production and investment for a biogas plant has been presented spanning the full supply chain from farmer to energy demand. The model has been applied to a specific location in Denmark. The case study shows that for the specific location, given the assumptions on efficiencies and costs, the plant should be built as large as possible within 
the given sizes and use methanation to upgrade the biogas to biomethane to increase income from biogas sales and to cover the heat demand in the region.

The inclusion of the output side is utilized by using a gas storage and a heat storage and therefore the biogas can be used when the demand of heat is present or stored considering the cost of storage.

The paper demonstrates that by careful planning of the complete supply chain, profitable biogas plants can be constructed. Even though the model gives an overall profitable solution, it does not ensure all stakeholders will get their share of the profit which might spoil the motivation for participating in the project. Therefore, it is interesting to study how the model can ensure a fair distribution of profit among the stakeholders.

\section{Acknowledgement}

This article is written as part of the BioChain project funded by the Danish Council of Strategic Research (DSF) with grant number 12-132631. We would also like to thank the reviewers for their valuable comments.

\section{References}

Abildgaard, L. (2016). SEGES, Personal communication.

Ahuja, R. K., Magnanti, T. L., \& Orlin, J. B. (1993). Network flows: theory, algorithms, and applications. Prentice Hall,.

Akhtari, S., Sowlati, T., \& Day, K. (2014). Optimal flow of regional forest biomass to a district heating system. International Journal of Energy Research, 38, 954-964. doi:10.1002/er.3099.

An, H., Wilhelm, W. E., \& Searcy, S. W. (2011). Biofuel and petroleum-based fuel supply chain research: A literature review. Biomass and Bioenergy, 35, 3763-3774. doi:10.1016/j.biombioe.2011.06.021.

Ba, B. H., Prins, C., \& Prodhon, C. (2016). Models for optimization and performance evaluation of biomass supply chains: An Operations Research perspective. Renewable Energy, 87, Part 2, 977-989. doi:10.1016/j.renene. 2015.07 .045 .

Beale, E. M. L., \& Tomlin, J. A. (1970). Special Facilities in a General Mathematical Programming System for Non-convex Problems Using Ordered Sets of Variables. Operations Research, 69, 447-454.

Birkmose, T., Hjort-Gregersen, K., \& Stefanek, K. (2013). Biomasse til biogasanlæg i Danmark - på kort og langt sigt (Biomass to biogas plants in Denmark-in the short and long run), . (pp. 1-63). URL: https://ens.dk/ sites/ens.dk/files/Bioenergi/biomasser_til_biogasanlaeg.pdf. Accessed 2016-09-21. 
Boldrin, A., Baral, K. R., Fitamo, T., Vazifehkhoran, A. H., Jensen, I. G., Kjærgaard, I., Lyng, K.-A., Nguyen, Q. V., Nielsen, L. S., \& Triolo, J. M. (2016). Optimized biogas production from co-digestion of sugar beet with pig slurry : integrating energy, GHG and economic accounting. Energy, 112, 606-617. doi:10.1016/j.energy.2016.06.068.

Börjesson, M., \& Ahlgren, E. O. (2012). Cost-effective biogas utilisation - A modelling assessment of gas infrastructural options in a regional energy system. Energy, 48, 212-226. doi:10.1016/j .energy . 2012.06.058.

Chen, C.-W., \& Fan, Y. (2012). Bioethanol supply chain system planning under supply and demand uncertainties. Transportation Research Part E: Logistics and Transportation Review, 48, 150-164. doi:10.1016/j.tre.2011.08. 004.

Danish Energy Agency (2012a). Danmarks energifremskrivning 2012 (Denmark's energy projection 2012). (October 11 ed.). URL: https://ens.dk/sites/ens.dk/files/Basisfremskrivning/danmarks_energifremskrivning_ 2012_endelig_v1.2.pdf accessed 2016-09-21.

Danish Energy Agency (2012b). Technology data for energy plants. May. URL: http://www.energinet.dk/ SiteCollectionDocuments/Danske\%20dokumenter/Forskning/Technology_data_for_energy_plants .pdf accessed 2016-09-21.

Danish Energy Agency (2014a). Analyse af bioenergi i Danmark (Analysis of bioenergy in Denmark), . URL: https://ens.dk/sites/ens.dk/files/Bioenergi/bioenergi_-_analyse_2014_web.pdf. Accessed 2016-09-21.

Danish Energy Agency (2014b). Biogas i Danmark - status , barrierer og perspektiver (Biogas in Denmarkstatus, barriers, and perspectives), .(p. 102). URL: https://ens.dk/sites/ens.dk/files/Bioenergi/biogas_ i_danmark_-_analyse_2014-final.pdf. Accessed 2016-09-21.

De Meyer, A., Cattrysse, D., Rasinmäki, J., \& Van Orshoven, J. (2014). Methods to optimise the design and management of biomass-for-bioenergy supply chains: A review. Renewable and Sustainable Energy Reviews, 31, 657-670. doi:10.1016/j.rser.2013.12.036.

De Meyer, A., Cattrysse, D., \& Van Orshoven, J. (2015). A generic mathematical model to optimise strategic and tactical decisions in biomass-based supply chains (OPTIMASS). European Journal of Operational Research, 245, 247-264. doi:10.1016/j .ejor.2015.02.045.

EA Energianalyse (2014). Anvendelse af biogas til el- og varmeproduktion (Use of biogas for power and heat production). Technical Report. URL: https://ens.dk/sites/ens.dk/files/Bioenergi/anvendelse_af_biogas_til_ el_og_varme_2.pdf accessed 2016-09-21.

Ekşioğlu, S. D., Acharya, A., Leightley, L. E., \& Arora, S. (2009). Analyzing the design and management of biomassto-biorefinery supply chain. Computers $\&$ Industrial Engineering, 57, 1342-1352. doi:10.1016/j.cie.2009.07. 003.

Eriksson, L. O., \& Björheden, R. (1989). Optimal storing, transport and processing for a forest-fuel supplier. European Journal of Operational Research, 43, 26-33. doi:10.1016/0377-2217(89)90406-2.

Evald, A., Hu, G., \& Hansen, M. T. (2013). Technology data for advanced bioenergy fuels. Technical Report. URL: https://ens.dk/sites/ens.dk/files/Analyser/l_teknologikatalog_for_konvertering_af_biomasse_til_ biobraendsler_2014.pdf accessed 2016-09-21.

Gebreslassie, B., Yao, Y., \& You, F. (2012). Design Under Uncertainty of Hydrocarbon Biorefinery Supply Chains: Multiobjective Stochastic Programming Models Decomposition Algorithm and a Comparison between CVaR and 
Downside Risk. AIChE Journal, 58, 2155-2179. doi:10.1002/aic.13844.

Huang, Y., Chen, C.-W., \& Fan, Y. (2010). Multistage optimization of the supply chains of biofuels. Transportation Research Part E: Logistics and Transportation Review, 46, 820-830. doi:10.1016/j.tre.2010.03.002.

Huang, Y. E., Fan, Y., \& Chen, C.-W. (2014). An Integrated Biofuel Supply Chain to Cope with Feedstock Seasonality and Uncertainty. Transportation Science, 48, 540-554. doi:10.1287/trsc.2013.0498.

Iakovou, E., Karagiannidis, a., Vlachos, D., Toka, a., \& Malamakis, a. (2010). Waste biomass-to-energy supply chain management: a critical synthesis. Waste management (New York, N.Y.), 30, 1860-70. doi:10.1016/j.wasman. 2010.02 .030 .

Kim, J., Realff, M. J., \& Lee, J. H. (2011). Optimal design and global sensitivity analysis of biomass supply chain networks for biofuels under uncertainty. Computers \& Chemical Engineering, 35, 1738-1751. doi:10.1016/j . compchemeng. 2011.02.008.

Pizarro, A. R. (2014). Optimization of Biogas Use - A Modeling Assessment. Master's thesis Technical University of Denmark.

Shabani, N., \& Sowlati, T. (2013). A mixed integer non-linear programming model for tactical value chain optimization of a wood biomass power plant. Applied Energy, 104, 353-361. doi:10.1016/j . apenergy . 2012.11.013.

Sharma, B., Ingalls, R., Jones, C., \& Khanchi, a. (2013). Biomass supply chain design and analysis: Basis, overview, modeling, challenges, and future. Renewable and Sustainable Energy Reviews, 24, 608-627. doi:10.1016/j.rser. 2013.03 .049 .

Van Dyken, S., Bakken, B. H., \& Skjelbred, H. I. (2010). Linear mixed-integer models for biomass supply chains with transport, storage and processing. Energy, 35, 1338-1350. doi:10.1016/j.energy.2009.11.017.

Wenzel, H., Høibye, L., Duban Grandal, R., Hamelin, L., Bird, D. N., \& Olesen, A. (2014). Carbon footprint of bioenergy pathways for the future Danish energy system. Technical Report March. URL: https: //ens.dk/sites/ens.dk/files/Bioenergi/carbon_footprint_of_bioeneergy_pathways_for_the_future_ danish_energy_system_-_final_210314_1.pdf accessed 2017-02-03.

Zhang, J., Osmani, A., Awudu, I., \& Gonela, V. (2013). An integrated optimization model for switchgrass-based bioethanol supply chain. Applied Energy, 102, 1205-1217. doi:10.1016/j.apenergy.2012.06.054. 


\section{Appendix A. Nomenclature}

\section{Parameters}

$A M_{i, n^{\prime}}$ Accumulated amount of biomass for biomass type $i$ in breakpoint $n^{\prime}$

$A_{j}$ Area of circle $j$

$T$ Hours on the input side

$T$ Number of weeks in a year

$\Delta A_{j}$ Average area of circle $j$ and circle $j-1$

$\Delta d_{i, n^{\prime}}\left(\Delta d_{n^{\prime}}^{d i g}\right)$ Average transportation distance for biomass $i$ (digestate) in breakpoint $n$

$\Delta r_{j}$ Average distance from center to the biomasses in circle $j$

$\eta^{E C}$ Percentage energy crops allowed in input mix

$\eta^{\text {available }}$ Amount not flared

$\eta^{\text {plant }}$ Mass after biogas plant $\%$

$\eta_{i, p^{\prime}, p} / \bar{\eta}_{p^{\prime}, p}$ Mass left after process $p$ coming from process $p^{\prime}$

$\gamma$ Percentage of mass of supplied manure that can be returned as digestate

$\bar{\eta}_{i}$ Initial biogas yield of biomass $i$

$\bar{\rho}_{p, t}$ Price of end product $p$ in time $t$

$\rho^{d i g}$ Price of digestate

$\rho_{p}^{\text {support }}$ Support process $p$

$a m_{i, m}\left(a m_{m}^{d i g}\right)$ Amount of biomass (digestate) transported on segment $m$

$a m_{i, n^{\prime}}\left(a m_{n^{\prime}}^{d i g}\right)$ Amount of biomass (digestate) in the annulus between $n^{\prime}$ and $n^{\prime}-1$

$b_{n}^{\text {plant }}$ Max. capacity of plant in breakpoint $n$

$b_{i, t}$ Biomass $i$ available at time $t$

$c^{H A N D L I N G, d i g}$ Handling cost of digestate

$c_{n}^{O P E X, S O S 2} / c_{n}^{C A P E X, S O S 2}$ OPEX/ CAPEX in breakpoint $n$ for the plant

$c_{i, p, t}^{O P X, v a r}$ Variable OPEX for input type $i$, process $p$ and time $t$

$c_{i, p}^{O P E X} / c_{i, p}^{C A P E X}\left(\bar{c}_{p}^{O P E X} /\right.$

$\bar{c}_{p}^{C A P E X}$ ) OPEX/CAPEX for biomass (gas) process $p$ for input type $i$

$c_{i, m}^{T R A N S}\left(c_{m}^{T R A N S, x d i g}\right)$ Transport cost for biomass type $i$ (digestate not sent to the manure supplier) on each segment $m$

$c_{i}^{\text {prod }}$ Production cost of biomass type $i$

$c_{i}^{\text {load }} / c_{i}^{\text {unload }}\left(c^{\text {load,dig }} / c^{\text {unload,dig }}\right)$ Cost of loading/unloading biomass $i$ (digestate)

$c_{i}^{\text {truck }}\left(c^{\text {truck,dig }}\right)$ Cost of using truck for biomass $i$ (digestate)

$c_{i, n^{\prime}}^{T R A N S}$ Cost of each biomass type transported to the plant in each breakpoint $n^{\prime}$

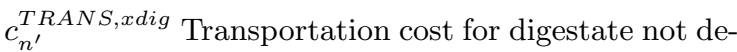
livered to the manure suppliers in breakpoint $n$

$d_{p, t}$ Demand of end product in hour $t$ - only defined for heat

$f_{p}$ Fixed amount going to process $p$ from a $\mathcal{P}^{K}$ process

$k_{i}^{\text {truck }}\left(k^{\text {truck,dig }}\right)$ Capacity of the truck used for transportation of biomass $i$ (digestate)

$r_{j}$ Radius of circle $j$

$t_{i, p}^{\min }$ Minimum process time of process $p$ for input type $i$

$t_{i}^{\text {load }} / t_{i}^{\text {unload }}\left(t^{\text {load,dig }} / t^{\text {unload,dig }}\right)$ Time used for loading/unloading biomass $i$ (digestate)

$v_{i}\left(v^{d i g}\right)$ Velocity of truck used for transportation of biomass $i$ (digestate) 


\section{Sets}

$\mathcal{A}\left(v^{\prime}, v\right)\left(\overline{\mathcal{A}}\left(v^{\prime}, v\right)\right)$ Arcs from vertex $v^{\prime}$ to vertex $v$ $\mathcal{A}^{-}(v) / \mathcal{A}^{+}(v)\left(\overline{\mathcal{A}}^{-}(v) / \overline{\mathcal{A}}^{+}(v)\right)$ Input (output) side arcs entering/leaving vertex $v$

$\mathcal{A}_{\text {cap }}^{-}(v)\left(\overline{\mathcal{A}}_{\text {cap }}^{-}(v)\right)$ Arcs to vertex $v$ used in capacity constraint

$\mathcal{A}_{\text {proc }}\left(v, v^{\prime \prime}\right)\left(\overline{\mathcal{A}}_{\text {proc }}\left(v, v^{\prime \prime}\right)\right)$ Process time arcs from vertex $v$ to vertex $v^{\prime \prime}$

$\mathcal{E}$ The set of possible energy content

$\mathcal{I}^{E C}$ Subset of biomasses that are energy crops

$\mathcal{I}$ Biomass types

$\mathcal{M}$ Line segments

$\mathcal{N}$ breakpoints

$\mathcal{P}(\overline{\mathcal{P}})$ Input (output) processes

$\mathcal{P}^{F}$ Farmer processes

$\mathcal{P}^{I}\left(\overline{\mathcal{P}}^{I}\right)$ Inner processes

$\mathcal{P}^{P}\left(\overline{\mathcal{P}}^{P}\right)$ The plant process on the input (output) side

$\mathcal{P}^{T}$ Transportation processes

$\mathcal{T} / \overline{\mathcal{T}}$ Input (output) time steps

$\mathcal{V}(\overline{\mathcal{V}})$ Input (output) vertices

$\mathcal{V}^{F}$ Vertices of farmer processes

$\mathcal{V}^{I}\left(\overline{\mathcal{V}}^{I}\right)$ Vertices of the inner processes

$\mathcal{V}^{M}$ Vertices of the manure farmer's process

$\mathcal{V}^{P}\left(\overline{\mathcal{V}}^{P}\right)$ Plant vertices on the input (output) side

$\mathcal{V}^{T}$ Vertices of the transportation processes

$\overline{\mathcal{A}}_{\text {decide }}^{+}(v)$ The set of arcs leaving vertex $v$ which de- fines the capacity of the process it leaves

$\overline{\mathcal{A}}_{\text {extra }}^{+}(v)$ The set of arcs with origin in vertex $v$ but not of the main type

$\overline{\mathcal{A}}_{\text {main }}^{+}(v)$ The set of arcs leaving vertex $v$ and arriving in a process that are of the main type

$\overline{\mathcal{P}}^{E}$ End processes

$\overline{\mathcal{P}}^{H}$ End process for heat

$\overline{\mathcal{P}}^{J}$ Processes on the output side with capacity spec-

ified on output

$\overline{\mathcal{P}}^{K}$ Processes where the inflow is fixed

$\overline{\mathcal{V}}^{E}$ Vertices of the end processes

$\overline{\mathcal{V}}^{H}$ End vertex for heat

$\overline{\mathcal{V}}^{J}$ Vertices on the output side with capacity specified on output

$\overline{\mathcal{V}}^{K}$ Vertices where the inflow is fixed

\section{Variables}

$k_{n}^{S O S 2}$ If the size of the plant is near breakpoint $n$ $k_{i, p} / \bar{k}_{p}$ Capacity of biomass/gas process $p$ for biomass type $i$

$x_{p, t}^{\text {left }}$ Not sold due to lack of demand

$x \neg$ manure Digestate not sent to manure suppliers

$x_{m}^{\text {trans,xdig }}$ Extra digestate transported on segment $m$ $x_{n}^{S O S 2}$ Biomasses to the plant in breakpoint $n$

$x_{a} / \bar{x}_{a}$ Flow on biomass/gas arc $a$

$x_{i, m}^{\text {trans }}$ Biomass $i$ transported on segment $m$

\section{Appendix B. Model}

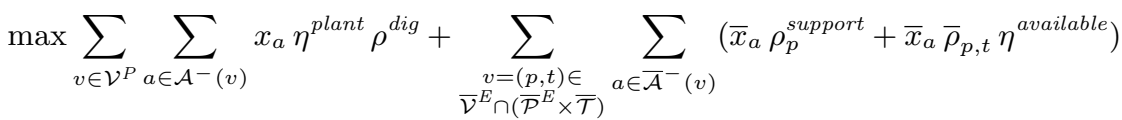

$$
\begin{aligned}
& -\sum_{p \in \overline{\mathcal{P}}} \sum_{t \in \overline{\mathcal{T}}} x_{p, t}^{\text {left }} \bar{\rho}_{p, t} \eta^{\text {available }}-\sum_{\substack{v=(i, p, t, e) \in \\
\mathcal{V}^{F} \cap\left(\mathcal{I} \times \mathcal{P}^{F} \times \mathcal{T} \times \mathcal{E}\right)}} \sum_{\substack{a \in \mathcal{A}^{+}(v) \\
x_{a}}} x_{i}^{\text {prod }}
\end{aligned}
$$




$$
\begin{aligned}
- & \sum_{\substack{v=(i, p, t, e) \in \\
\mathcal{V} \cap(\mathcal{I} \times \mathcal{P} \times \mathcal{T} \times \mathcal{E})}} \sum_{a \in \mathcal{A}^{-}(v)} x_{a}\left(c_{i, p}^{O P E X}+c_{i, p, t}^{O P E X, v a r}\right)-\sum_{\substack{v=(p, t) \in \\
\mathcal{\mathcal { V }} \cap(\overline{\mathcal{P}} \times \overline{\mathcal{T}})}} \sum_{a \in \overline{\mathcal{A}}^{-}(v)} \bar{x}_{a} \bar{c}_{p}^{\text {OPEX }} \\
- & \sum_{i \in \mathcal{I}} \sum_{p \in \mathcal{P}} k_{i, p} \frac{T}{t_{i, p}^{\text {min }}} c_{i, p}^{\text {CAPEX }}-\sum_{p \in \overline{\mathcal{P}}} \bar{k}_{p} \bar{c}_{p}^{\text {CAPEX }}-\sum_{n \in \mathcal{N}} x_{n}^{\text {SOS2 }} c_{n}^{\text {OPEX }, \text { SOS2 }} \\
- & \sum_{n \in \mathcal{N}} k_{n}^{\text {SOS2 }} c_{n}^{\text {CAPEX,SOS2 }}-\sum_{i \in \mathcal{I}} \sum_{m \in \mathcal{M}} x_{i, m}^{\text {trans }} c_{i, m}^{\text {TRANS }}-\sum_{m \in \mathcal{M}} x_{m}^{\text {trans }, x d i g} c_{m}^{\text {TRANS,xdig }} \\
- & \sum_{v \in \mathcal{V}^{P}} \sum_{a \in \mathcal{A}^{-}(v)} x_{a} \eta^{\text {plant }} c^{\text {HANDLING,dig }}
\end{aligned}
$$

Subject to:

$$
\begin{aligned}
& \sum_{\substack{v^{\prime}=\left(i^{\prime}, p^{\prime}, t^{\prime}, e^{\prime}\right) \in \\
\mathcal{V} \cap(\mathcal{I} \times \mathcal{P} \times \mathcal{T} \times \mathcal{E})}} \sum_{a \in \mathcal{A}\left(v^{\prime}, v\right)} x_{a} \eta_{i, p^{\prime}, p}=\sum_{a \in \mathcal{A}^{+}(v)} x_{a} \quad \forall v=(i, p, t, e) \in \mathcal{V}^{I} \cap\left(\mathcal{I} \times \mathcal{P}^{I} \times \mathcal{T} \times \mathcal{E}\right) \\
& \sum_{\substack{v^{\prime}=\left(i, p^{\prime}, t^{\prime}, e^{\prime}\right) \in \\
\mathcal{V} \cap(\mathcal{P} \times \mathcal{T} \times \mathcal{E}) \mid p \neq p^{\prime}}} \sum_{a \in \mathcal{A}\left(v^{\prime}, v\right)} x_{a} \eta_{i, p^{\prime}, p} \leq \sum_{\substack{v^{\prime \prime}=\left(i, p^{\prime \prime}, t^{\prime \prime}, e^{\prime \prime}\right) \in \\
\mathcal{V} \cap(\mathcal{P} \times \mathcal{T} \times \mathcal{E}) \mid p \neq p^{\prime \prime}}} \sum_{a \in \mathcal{A}_{p r o c}\left(v, v^{\prime \prime}\right)} \frac{x_{a}}{\left(\eta_{i, p, p}\right)^{t^{\prime \prime}-t}} \\
& \forall v=(i, p, t, e) \in \mathcal{V}^{I} \cap\left(\mathcal{I} \times \mathcal{P}^{I} \times \mathcal{T} \times \mathcal{E}\right) \\
& \sum_{v=(i, p, t, e) \in \mathcal{V} \cap \mathcal{E}} \sum_{a \in \mathcal{A}^{-}(v)} x_{a}+\sum_{v=(i, p, t, e) \in \mathcal{V} \cap \mathcal{E}} \sum_{a \in \mathcal{A}_{c a p}^{-}(v)} x_{a} \leq k_{i, p} \quad \forall(i, p, t) \in \mathcal{I} \times \mathcal{P} \times \mathcal{T} \\
& \sum_{a \in \mathcal{A}^{+}(v)} x_{a} \leq b_{i, t} \quad \forall v=(i, p, t, e) \in \mathcal{V}^{F} \cap\left(\mathcal{I} \times \mathcal{P}^{F} \times \mathcal{T} \times \mathcal{E}\right) \\
& \sum_{\substack{v=(i, p, t, e) \in \\
\mathcal{V}^{P} \cap\left(\mathcal{I}^{E C} \times \mathcal{P}^{P} \times \mathcal{E}\right)}} \sum_{a \in \mathcal{A}^{-}(v)} x_{a} \leq \eta^{E C} \sum_{\substack{v=(i, p, t, e) \in \mathcal{V}^{P} \\
\cap\left(\mathcal{I} \times \mathcal{P}^{P} \times \mathcal{E}\right)}} \sum_{a \in \mathcal{A}^{-}(v)} x_{a} \quad \forall t \in \mathcal{T} \\
& \sum_{v \in \mathcal{V}^{P}} \sum_{a \in \mathcal{A}^{-}(v)} x_{a}=\sum_{n \in \mathcal{N}} b_{n}^{\text {plant }} x_{n}^{S O S 2} \\
& \sum_{n \in \mathcal{N}} x_{n}^{S O S 2}=1 \\
& \sum_{n \in \mathcal{N}} b_{n}^{\text {plant }} k_{n}^{S O S 2}=\sum_{i \in \mathcal{I}} \sum_{p \in \mathcal{P}^{P}} \frac{T}{t_{i, p}^{\min }} k_{i, p} \\
& \sum_{n \in \mathcal{N}} k_{n}^{S O S 2}=1 \\
& b_{1}^{\text {plant }} \leq \sum_{i \in \mathcal{I}} \sum_{p \in \mathcal{P}^{P}} \frac{T}{t_{i, p}^{m i n}} k_{i, p} \leq b_{\text {end }}^{\text {plant }} \\
& \sum_{\substack{v^{\prime}=\left(p^{\prime}, t^{\prime}\right) \in \\
\overline{\mathcal{V}} \cap(\overline{\mathcal{P}} \times \overline{\mathcal{T}})}} \sum_{a \in \overline{\mathcal{A}}\left(v^{\prime}, v\right)} \bar{x}_{a} \bar{\eta}_{p^{\prime}, p}=\sum_{a \in \overline{\mathcal{A}}^{+}(v)} \bar{x}_{a} \quad \forall v=(p, t) \in \overline{\mathcal{V}}^{I} \cap\left(\overline{\mathcal{P}}^{I} \times \overline{\mathcal{T}}\right) \\
& \sum_{\substack{v^{\prime}=\left(p^{\prime}, t^{\prime}\right) \in \\
\mathcal{V} \cap(\overline{\mathcal{P}} \times \overline{\mathcal{T}}) \mid p \neq p^{\prime}}} \sum_{a \in \overline{\mathcal{A}}\left(v^{\prime}, v\right)} \bar{x}_{a} \bar{\eta}_{p^{\prime}, p} \leq \sum_{\substack{v^{\prime \prime}=\left(p^{\prime \prime}, t^{\prime \prime}\right) \in \\
\mathcal{V} \cap(\overline{\mathcal{P}} \times \overline{\mathcal{T}}) \mid p \neq p^{\prime \prime}}} \sum_{a \in \overline{\mathcal{A}}_{\text {proc }}\left(v, v^{\prime \prime}\right)} \frac{\bar{x}_{a}}{\left(\bar{\eta}_{p p}\right)^{t^{\prime \prime}-t}} \quad \forall v=(p, t) \in \overline{\mathcal{V}}^{I} \cap\left(\overline{\mathcal{P}}^{I} \times \overline{\mathcal{T}}\right) \\
& \sum_{v=(p, t) \in \overline{\mathcal{V}}_{a \in \overline{\mathcal{A}}^{-}}} \sum_{(v)} \bar{x}_{a}+\sum_{v=(p, t) \in \overline{\mathcal{V}}_{a \in \overline{\mathcal{A}}_{c a p}^{-}(v)}} \bar{x}_{a} \leq \bar{k}_{p} \quad \forall(p, t) \in \overline{\mathcal{P}} \times \overline{\mathcal{T}} \\
& \sum_{\substack{v=(p, t) \in \\
\overline{\mathcal{V}}^{P} \cap \overline{\mathcal{P}}^{P}}} \sum_{a \in \overline{\mathcal{A}}^{+}(v)} \bar{x}_{a}=\sum_{\substack{v=\left(i, p,\left\lfloor\frac{t}{\overline{7} \cdot 24}\right\rfloor+1, e\right) \\
\in \overline{\mathcal{V}}^{P} \cap\left(\mathcal{I} \times \overline{\mathcal{P}}^{P} \times \mathcal{E}\right)}} \sum_{a \in \mathcal{A}^{-}(v)} \frac{x_{a} \bar{\eta}_{i} e}{7 \cdot 24} \quad \forall t \in \overline{\mathcal{T}}
\end{aligned}
$$




$$
\begin{aligned}
& \sum_{a \in \overline{\mathcal{A}}_{\text {decide }}^{+}(v)} \bar{x}_{a} \leq \bar{k}_{p} \quad \forall v=(p, t) \in \overline{\mathcal{V}}^{J} \cap\left(\overline{\mathcal{P}}^{J} \times \overline{\mathcal{T}}\right) \\
& \bar{x}_{a}=f_{p} \sum_{a^{\prime} \in \overline{\mathcal{A}}_{\text {extra }}^{+}(v)} \bar{x}_{a^{\prime}} \quad \forall v=(p, t) \in \overline{\mathcal{V}}^{K} \cap\left(\overline{\mathcal{P}}^{K} \times \mathcal{T}\right), a \in \overline{\mathcal{A}}_{\text {main }}^{+}(v) \\
& \sum_{a \in \overline{\mathcal{A}}(v)} \bar{x}_{a} \leq d_{p, t}+x_{p, t}^{\text {left }} \quad \forall v=(p, t) \in \overline{\mathcal{V}}^{H} \cap\left(\overline{\mathcal{P}}^{H} \times \overline{\mathcal{T}}\right) \\
& \sum_{m \in \mathcal{M}} x_{i, m}^{\text {trans }}=\sum_{\substack{v=(i, p, t, e) \in \\
\mathcal{V}^{T} \cap\left(\mathcal{P}^{T} \times \mathcal{T} \times \mathcal{E}\right)}} \sum_{a \in \mathcal{A}^{+}(v)} x_{a} \quad \forall i \in \mathcal{I} \\
& x_{i, m}^{\text {trans }} \leq a m_{i, m} \quad \forall i \in \mathcal{I}, m \in \mathcal{M} \\
& x^{\urcorner \text {manure }} \geq \sum_{\substack{v=(i, p, t, e) \in \\
\mathcal{V}^{P} \cap\left(\mathcal{P}^{P} \times \mathcal{T} \times \mathcal{E}\right)}} \sum_{a \in \mathcal{A}^{-}(v)} x_{a} \eta^{\text {plant }}-\sum_{v \in \mathcal{V}^{M}} \sum_{a \in \mathcal{A}^{+}(v)} x_{a} \gamma \\
& x_{m}^{\text {trans,xdig }} \leq a m_{m}^{\text {dig }} \quad \forall m \in \mathcal{M} \\
& \sum_{m \in \mathcal{M}} x_{m}^{\text {trans,xdig }} \leq x^{\neg \text { manure }} \\
& x_{a} \geq 0 \quad \forall a \in \mathcal{A} \\
& \bar{x}_{a} \geq 0 \quad \forall a \in \overline{\mathcal{A}} \\
& x_{p, t}^{\text {left }} \geq 0 \quad \forall p \in \overline{\mathcal{P}}, t \in \overline{\mathcal{T}} \\
& k_{i, p} \geq 0 \quad i \in \mathcal{I}, p \in \mathcal{P} \\
& \bar{k}_{p} \geq 0 \quad \forall p \in \overline{\mathcal{P}} \\
& x_{n}^{S O S 2}, k_{n}^{S O S 2} \in S O S 2 \quad \forall n \in \mathcal{N} \\
& x_{i, m}^{\text {trans }} \geq 0 \quad \forall i \in \mathcal{I}, m \in \mathcal{M} \\
& x_{m}^{\text {trans }, x d i g} \geq 0 \quad \forall m \in \mathcal{M} \\
& x^{\urcorner \text {manure }} \geq 0
\end{aligned}
$$




\section{Appendix C. Data}

\begin{tabular}{|c|c|c|c|c|c|c|c|}
\hline \multicolumn{8}{|l|}{ Sugar beet } \\
\hline Process & CAPEX & OPEX & Min. process time & Max. process time & Efficiency, $\eta_{i, p^{\prime}, p}$ & Efficiency, $\eta_{i, p, p}$ & Energy efficiency \\
\hline Storage1 & 0.25 & 1.61 & 1 & 16 & $100 \%$ & $100 \%$ & $0 \%$ \\
\hline Washer & 0 & 2.57 & 1 & 1 & $100 \%$ & $100 \%$ & $0 \%$ \\
\hline Storage2 & 0.25 & 1.61 & 1 & 4 & $100 \%$ & $100 \%$ & $0 \%$ \\
\hline Cutter & 0 & 2.14 & 1 & 1 & $100 \%$ & $100 \%$ & $0 \%$ \\
\hline Ensilage & 0.11 & 1.61 & 26 & 52 & $85 \%$ & $100 \%$ & $2 \%$ \\
\hline Storage3 & 0.25 & 1.61 & 1 & 4 & $100 \%$ & $100 \%$ & $-10 \%$ \\
\hline \multicolumn{8}{|l|}{ Manure } \\
\hline Process & CAPEX & OPEX & Min. process time & Max. process time & Efficiency, $\eta_{i, p^{\prime}, p}$ & Efficiency, $\eta_{i, p, p}$ & Energy efficiency \\
\hline Storage1 & 0.25 & 0 & 1 & 4 & $100 \%$ & $100 \%$ & $0 \%$ \\
\hline Storage2 & 0.25 & 0 & 1 & 4 & $100 \%$ & $100 \%$ & $0 \%$ \\
\hline \multicolumn{8}{|l|}{ Straw } \\
\hline Process & CAPEX & OPEX & Min. process time & Max. process time & Efficiency, $\eta_{i, p^{\prime}, p}$ & Efficiency, $\eta_{i, p, p}$ & Energy efficiency \\
\hline Storage1 & 1.90 & 0 & 1 & 52 & $100 \%$ & $100 \%$ & $0 \%$ \\
\hline Briquetting & 3.88 & 10.18 & 1 & 1 & $100 \%$ & $100 \%$ & $20 \%$ \\
\hline Storage2 & 0.95 & 0 & 1 & 52 & $100 \%$ & $100 \%$ & $0 \%$ \\
\hline
\end{tabular}

Table C.1: Data for the case study —input side. OPEX are in $€ 2015 /$ ton and all CAPEX are annualized with a rate of return of $5 \%$ and the given lifetime of the process (20 years are used when no data) and are in $€ 2015 /$ ton/year. All data for sugar beet and manure are from (Boldrin et al., 2016). The data for straw are from (Abildgaard, 2016). 


\begin{tabular}{l|cccc}
\hline \hline Biomass type & $\begin{array}{c}\text { Production cost and } \\
\text { transport to farm } € / \text { ton }\end{array}$ & $\begin{array}{c}\text { Biogas yield } \\
N m^{3} B G / \text { ton }\end{array}$ & $\begin{array}{c}\text { Extra CAPEX } \\
€ / \text { ton/year }\end{array}$ & $\begin{array}{c}\text { Extra OPEX } \\
€ / \text { ton }\end{array}$ \\
\hline Sugar beet & 23 & 108.6 & 0.54 & 2.41 \\
Manure & 6 & 12.6 & 0 & 0 \\
Straw & 28 & 317 & 4.62 & 15.41 \\
\hline
\end{tabular}

Table C.2: Production costs and biogas yields of the biomass types. The production costs for sugar beet and straw, i.e. without any storage costs etc., as well as transportation costs to the farm are given by (Abildgaard, 2016). From the field to the farmer, we assume a distance of $1.5 \mathrm{~km}$ for sugar beet and $1.9 \mathrm{~km}$ for straw. The production cost and biogas yield of manure are from (Boldrin et al., 2016). The biogas yield and extra CAPEX and OPEX for sugar beet and straw are from (EA Energianalyse, 2014).

\begin{tabular}{|c|c|c|c|c|c|c|c|c|c|c|c|c|}
\hline \multirow[b]{2}{*}{ Radius } & \multicolumn{3}{|c|}{ Sugar beet } & \multicolumn{3}{|c|}{ Manure } & \multicolumn{3}{|c|}{ Straw } & \multicolumn{3}{|c|}{ Digestate } \\
\hline & $a m_{i, n^{\prime}}$ & $\Delta d_{i, n^{\prime}}$ & $c_{i, m}^{T R A N S}$ & $a m_{i, n^{\prime}}$ & $\Delta d_{i, n^{\prime}}$ & $c_{i, m}^{T R A N S}$ & $a m_{i, n^{\prime}}$ & $\Delta d_{i, n^{\prime}}$ & $c_{i, m}^{T R A N S}$ & $a m_{i, n^{\prime}}$ & $\Delta d_{n^{\prime}}$ & $c_{m}^{T R A N S, d i g}$ \\
\hline 5 & 0 & 4 & 0.00 & 45089 & 4 & 0.81 & 10926 & 4 & 5.90 & 14080 & 4 & 0.40 \\
\hline 10 & 1159 & 8 & 2.63 & 166934 & 7 & 1.33 & 26094 & 7 & 6.91 & 37240 & 7 & 0.90 \\
\hline 15 & 1545 & 11 & 3.12 & 304074 & 10 & 1.91 & 24385 & 9 & 8.02 & 109521 & 11 & 1.45 \\
\hline 20 & 3508 & 15 & 3.63 & 455056 & 14 & 2.49 & 29203 & 12 & 9.16 & & & \\
\hline 25 & 4035 & 18 & 4.14 & & & & 39645 & 15 & 10.30 & & & \\
\hline 30 & 2091 & 19 & 4.64 & & & & 62513 & 19 & 11.44 & & & \\
\hline 35 & 3687 & 22 & 5.15 & & & & 68058 & 23 & 12.59 & & & \\
\hline 40 & 4470 & 26 & 5.66 & & & & 73320 & 26 & 13.73 & & & \\
\hline 45 & 4178 & 29 & 6.17 & & & & 68590 & 29 & 14.88 & & & \\
\hline 50 & 2493 & 30 & 6.69 & & & & 78512 & 32 & 16.03 & & & \\
\hline 55 & 4606 & 34 & 7.20 & & & & 68458 & 34 & 17.18 & & & \\
\hline 60 & 5219 & 37 & 7.71 & & & & 57728 & 37 & 18.33 & & & \\
\hline 65 & 5643 & 40 & 8.22 & & & & 60372 & 39 & 19.48 & & & \\
\hline 70 & 4579 & 43 & 8.73 & & & & 78902 & 42 & 20.62 & & & \\
\hline 75 & 5440 & 46 & 9.24 & & & & 90134 & 45 & 21.77 & & & \\
\hline 80 & 4933 & 49 & 9.75 & & & & 101572 & 49 & 22.92 & & & \\
\hline $80+$ & 12414 & 54 & 10.00 & & & & & & & & & \\
\hline
\end{tabular}

Table C.3: Data for the case study - transportation. All costs are in $€ 2015$. Further, the handling price of digestate, $c^{H A N D L I N G, d i g_{a l l}}$, is $0.40 € /$ ton. Data for the last radii is kept out for the types where it is not needed due to too large costs etc. The amount of input in each circle for straw as well as transportation costs for all substrates are data from (Abildgaard, 2016). The amount of input for sugar beet and manure are from (Boldrin et al., 2016). 


\begin{tabular}{|c|c|c|c|c|c|c|c|c|c|}
\hline Process & CAPEX & OPEXfix & OPEXvar & $\begin{array}{c}\text { Min. process } \\
\text { time }\end{array}$ & $\begin{array}{c}\text { Max. process } \\
\text { time }\end{array}$ & $\begin{array}{c}\text { Efficiency, } \\
\qquad \eta_{p^{\prime}, p}\end{array}$ & $\begin{array}{l}\text { Efficiency } \\
\text { same, } \eta_{p, p}\end{array}$ & $f_{p}$ & Main process $p$ \\
\hline Gas storage & 2.35 & & & 1 & 12 & 100 & 100 & & \\
\hline Ironadsorption & 28.25 & 162.4 & & 1 & 1 & 100 & & & \\
\hline Bio-scrubbing & 59.70 & 32.5 & & 1 & 1 & 100 & & & \\
\hline Bio-thrickling & 48.87 & 8.1 & & 1 & 1 & 100 & & & \\
\hline Water scrubbing & 120.36 & 30 & & 1 & 1 & 69.96 & & & \\
\hline Org. phys. scrubbing & 136.41 & 34 & & 1 & 1 & 70.67 & & & \\
\hline Press. swing absorption & 120.36 & 75 & & 1 & 1 & 71.77 & & & \\
\hline Chem. scrubbin & 120.36 & 45 & & 1 & 1 & 70.23 & & & \\
\hline Methanation & 561.70 & 150.5 & & 1 & 1 & 176.8 & & 6.75 & Natural gas \\
\hline Boiler & 6107.17 & 3700 & & 1 & 1 & 0.74 & & & \\
\hline SCGT & 42571.47 & & 3.4 & 1 & 1 & 0.62 & & 0.95 & Electricity \\
\hline CCGT & 78047.7 & & 2.5 & 1 & 1 & 0.67 & & 1.61 & Electricity \\
\hline Gas engine & 120427.86 & & 9.3 & 1 & 1 & 0.69 & & 0.92 & Electricity \\
\hline 7 to 40 & 57.37 & 20 & & 1 & 1 & 100 & & & \\
\hline 1 to 40 & 114.75 & 40 & & 1 & 1 & 100 & & & \\
\hline Heat storage & 46.80 & 4.07 & & 1 & 12 & 100 & 99.97 & & \\
\hline Nm3toMW & & & & 0 & 0 & 1.08 & & & \\
\hline
\end{tabular}

Table C.4: Data for the case study - output side (Danish Energy Agency, 2012b; Evald et al., 2013; Pizarro, 2014). All costs are in $€ 2015$ and all CAPEX's and fixed OPEX's are annualized with a rate of return of $5 \%$ and the given lifetime of the process (20 years are used in case of no data). CAPEX and OPEXfix are in $€ / \mathrm{Nm} 3 /$ year and OPEXvar is in €/Nm3 except for Boiler, Single-cycle gas turbine (SCGT), Combined-cycle gas turbine (CCGT), and Gas engine which are in $€ / M W /$ year and $€ / M W h$. 